\title{
REDESCRIPTION OF FOUR SPECIES OF THE GENUS TYROPHAGUS (ACARI: ACARIDAE) FROM WESTERN IRAN
}

\author{
Farshad Masoudian ${ }^{1 *}$, Mohammad Khanjani1*, Alireza Saboori ${ }^{2}$ \\ and Karim Hadad Irani-Nejad ${ }^{3}$
}

\begin{abstract}
${ }^{1}$ Department of Plant Protection, College of Agriculture, Bu-Ali Sina University, Hamedan, Iran ${ }^{2}$ Department of Plant Protection, Faculty of Agriculture, University of Tehran, Karaj, Iran ${ }^{3}$ Department of Plant Protection, Faculty of Agriculture, University of Tabriz, Iran *corresponding authors; e-mails: f.masoodian@gmail.com; mkhanjani@gmail.com
\end{abstract}

ABSTRACT: We redescribe four species of the genus Tyrophagus Oudemans (Acari: Acaridae): T. longior (Gervais), T. similis Volgin, T. vanheurni Oudemans and T. neiswanderi Johnston and Bruce, collected from the forest soil and tree litter in Hamedan province, Western Iran. We note minor differences between our specimens and other published descriptions of these species.

KEY WORDS: Mites, Sarcoptiformes, Tyrophagus, redescription, Iran.

DOI: 10.21684/0132-8077-2018-26-1-111-132

\section{INTRODUCTION}

The family Acaridae (Acari: Sarcoptiformes) is an ecologically diverse and cosmopolitan group that includes more than 90 genera and about 400 described species (OConnor 2009; Fan and Zhang 2007). The cosmopolitan genus Tyrophagus (with 35 valid species) was erected by Oudemans, 1924 with Acarus putrescentiae Schrank, 1781 as its type species (Fan and Zhang 2007). Most species of this genus are fungivorous. They are also commonly associated with stored products and have a substantial economic impact (Hughes 1976; Fan and Zhang 2007). Eight species of Tyrophagus have been recorded in Iran (Khanjani et al. 2000; Kamali et al. 2001; Hadad Iraninezhad et al. 2007; Lotfollahi et al. 2010). Namely, T. brevicrinatus Robertson, 1959; T. longior (Gervais, 1844); T. neiswanderi Johnston and Bruce, 1965; T. vanheurni Oudemans, 1924 [=T. palmarum Oudemans; sensu Robertson, 1959 (Fan and Zhang 2007)]; T. perniciosus Zakhvatkin 1941; T. putrescentiae (Schrank, 1781); T. similis Volgin 1949; T. zachvatkini Volgin 1948. In this paper, four species of Tyrophagus collected in the forested areas of Hamedan province, Western Iran are redescribed and illustrated. We also compare our specimens with those reported from New Zealand and other regions (Fan and Zhang, 2007). This manuscript also gives a key to females of the genus Tyrophagus from Iran.

\section{MATERIAL AND METHODS}

Specimens were collected from soil and forest litter. The mites were mounted in Hoyer's medium on microscope slides. Slides were dried in an oven $\left(50{ }^{\circ} \mathrm{C}\right)$, sealed with an industrial painting material, and examined under an Olympus BX51 Dif- ferential Interference Contrast (DIC) microscope. Drawings were made with a camera lucida and all measurements are presented in micrometers $(\mu \mathrm{m})$. The terminology and abbreviations follow that of Griffiths et al. (1990) for idiosomal chaetotaxy; Grandjean (1939) for leg chaetotaxy; and Klimov and OConnor (2003) for organotaxy.

\section{SYSTEMATICS}

Acaridae Latreille, 1802

Tyrophagus Oudemans, 1924: 250

Type species: Acarus putrescentiae Schrank, 1781

\section{Tyrophagus longior (Gervais, 1844): 262}

Diagnosis. Eyespots absent; $s c x$ slender, tapering from base to tip; ratio: $d 1 / c 11.46-1.50 ; d 1 / d 2$ $1.34-1.35$; $d 2 / c 11.10$; coxal plates I triangular; coxal plates II triangular with posterior margin slightly sinuous; spermathecal duct broad, widening gradually from midway to base of spermathecal sac; solenidion $\omega 1$ and $\omega$ of legs I-II slender and cylindrical and tapered distally; tarsus IV with setae $w$ and $r$ filiform.

Female (Figs. 1-12, 60, 65, 70, 75, 80, 85, 90, $95 ; \mathrm{n}=7$ ). Idiosoma oval. Length of body, including gnathosoma, 519-563, excluding gnathosoma 437-480; width 250-288.

Dorsum (Figs. 1-4, 60, 65). Prodorsal shield punctate, with two pairs of setae ( $v i$ and $v e$ ) almost pentagonal, with lateral margins slightly concave; 82-88 long, 97-102 wide between setae ve-ve. Eyespots absent (Figs. 1, 4, 60); basal lobe of Grandjean's organ with one large tooth and three small teeth, 15-20, 12-13, 5 and 2 long, respectively (Fig. 3). Supracoxal seta $s c x$ slender, tapering from 
F. Masoudian, M. Khanjani, A. Saboori and K.H. Irani-Nejad

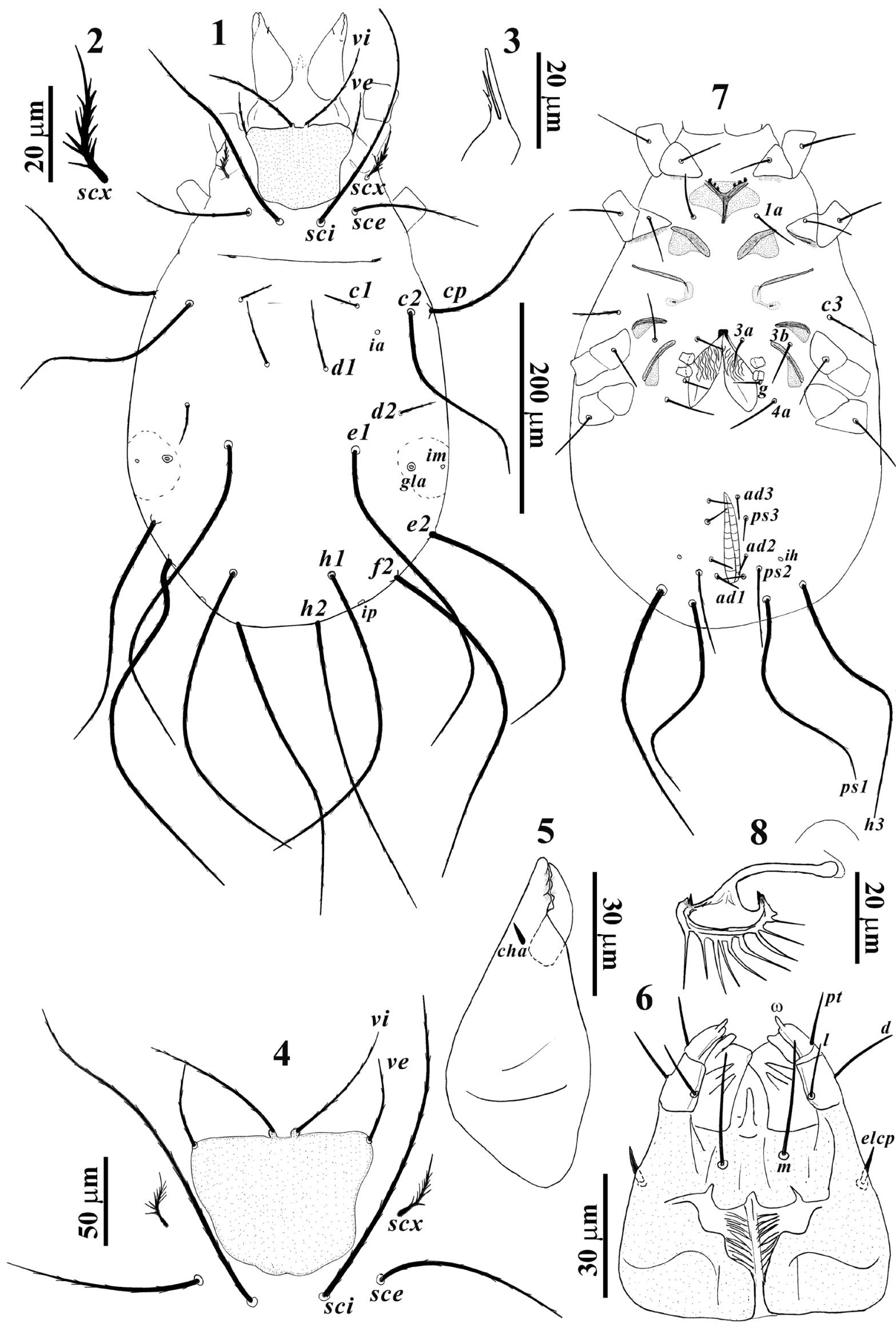

Figs. 1-8. T. longior (Gervais, 1844) (female): 1. dorsal view; 2. supracoxal seta (scx); 3. Grandjean's organ; 4. prodorsal shield; 5. chelicera; 6. gnathosoma; 7. ventral view; 8 . spermatheca. 


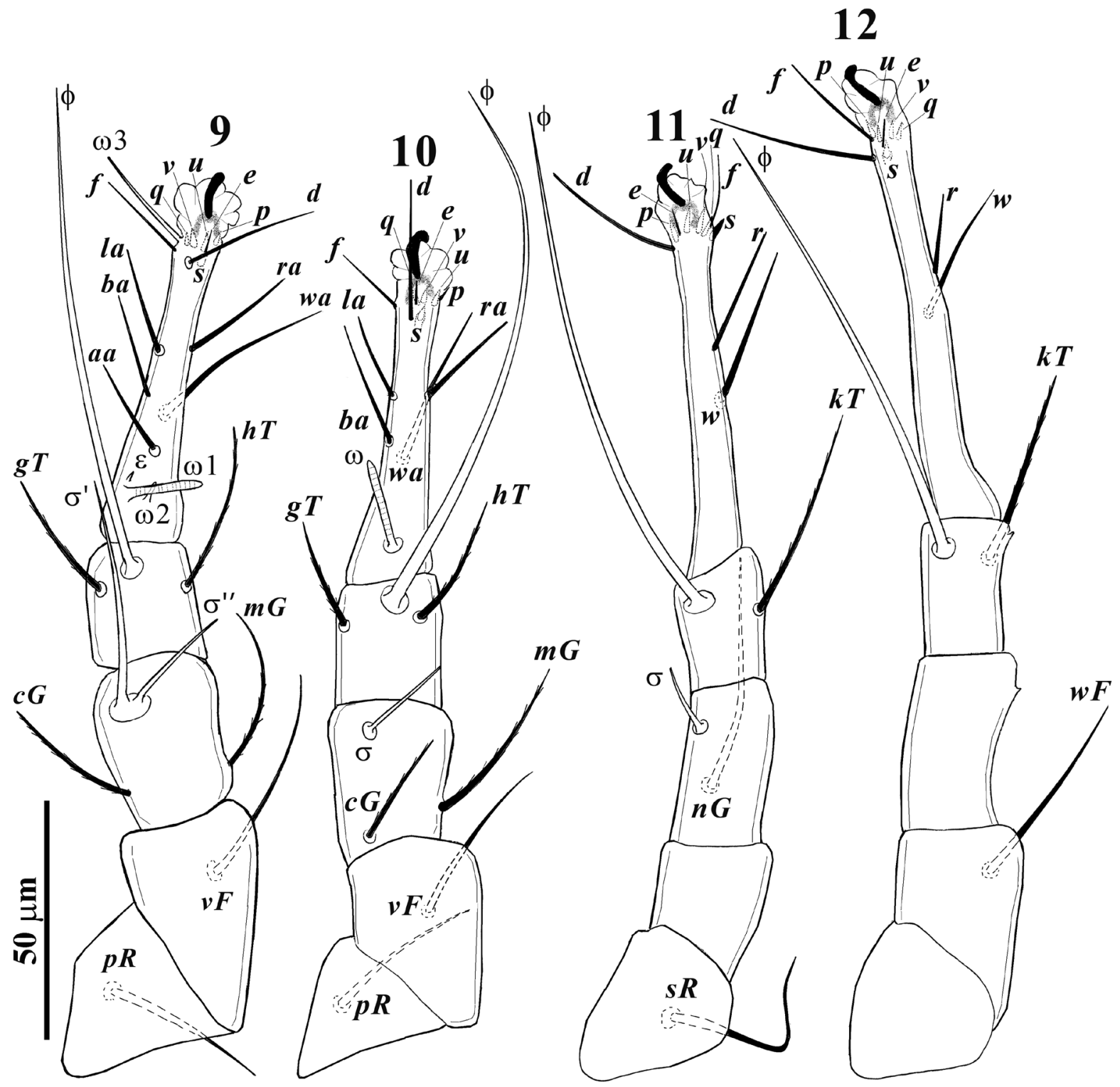

Figs. 9-12. T. longior (Gervais, 1844) (female): 9. leg I; 10. leg II; 11. leg III; 12. leg IV.

base to tip and with six-seven tines on each side (Figs. 1-2, 4, 65). All dorsal setae finely serrated. All opisthosomal setae whip-like except for $c 1, d 1$ and $d 2$. Dorsal opisthosoma with three pairs of cupules ( $\mathrm{ia}$, im and ip) and one pair of opisthosomal gland ( $g l a)$ at level of seta $e l$; seta $c l$ is the shortest, whereas seta $h 1-2$ are the longest dorsal setae; length of dorsal setae: vi 82-87; ve 40-55; sci 182-195; sce 112-128; scx 30-42; c1 32-38; c2 187-202; cp 125-138; d1 47-57; d2 35-42; e1 282-300; e2 207-212; f2 317-352; h1 295-350; h2 322-355. Distances: vi-vi 11-12; vi-ve 37-40; ve-ve 95-100; sce-sce 87-95; sci-sce 25; sci-sci 35-38; sce-ve 75-80; c1-c1 100-105; c1-c2 37-53; c2-c2 175207; $c 2-c p$ 30-35; $c p-c p$ 230-263; $c 1-d 1$ 42-63; $d 1-d 150-63 ; d 1-d 272-85 ; d 2-d 2$ 165-195; d2-gla
45-50; gla-gla 182-225; gla-el 42-53; e1-el 100-113; e1-e2 75-100; e2-e2 187-253; e2-f2 180-213; f2-f2 100-135; el-h1 102-115; h1-h1 65-88; h1-h2 40-50; h2-h2 67-85. Ratio: dl/cl 1.46-1.50; d1/d2 1.34-1.35; d2/cl 1.09-1.10.

Gnathosoma (Figs. 5-6). Punctate; palp tarsus with a simple seta $(p t)$ and one solenidion $(\omega) 13$ and 5-7 long, respectively; palp tibia with two simple setae ( $d 22-30$ and $l 18-23$ long); infracapitulum with one simple seta $(m)$ 32-37 long, distance: $m-m$ 19-23; palp coxa with one elcp setae 10-15 (Fig. 6); helicerae 85-100 long, cheliceral seta cha spine-like 6-7 long, movable and fixed digits with 4 teeth (Fig. 5).

Venter (Figs. 7-8, 70, 75, 95). Coxal plates I divided with apodemes I anteriorly on each side 
with three nodules; coxal plates II triangular and with an well-developed apodeme and distally not reaching apex of apodeme II (Figs. 7, 70, 75); with a pair of thin, sclerotized sejugal apodemes, 57-63 long, between coxae II and III; coxal plates III-IV each with apodemes (Fig. 7); genital region (posterior to sejugal apodemes to coxae IV) with a pair of setae $(\mathrm{g})$ and genital folds (Fig. 7). Anal region with three pairs of adanal setae ( $a d 1-3)$ and three pairs of pseudanal setae ( $p s 1-3)$, seta $p s 1$ the longest anal setae (Fig. 7); there is a pair of cupule $(i h)$ at level of seta $a d 2$ base. Copulatory opening (5-6 in diameter), spermathecal duct broad (26-30 long) and widening gradually from midway to base of spermathecal sac (Figs. 8, 95); length of ventral setae: $1 a$ 37-50, c3 30-35, 3a 20-25, 3b 37-45, 4a 50-53, g 13-18, ad3 13-18, ad2 15-20, ad1 17-20, ps3 22-25, ps2 77-90, ps 1 200-228, h3 262-300.

Legs (Figs. 9-12, 80, 85, 90). Solenidia $\omega 1$ and $\omega$ of legs I-II slender and cylindrical (Figs. 9-10, $80,85)$. Measurements of leg segments and setae as follows: $\operatorname{leg} I$ : $\operatorname{Tr} 35-38, p R$ 35-38, Fe 50-58, $v F$ 52-55, Ge 32-38, $c G$ 32-40, $m G$ 45-50, $\sigma 1$ 52-63, o2 25-32, Ti 30-38, gT 25-38, hT 32-43, $\varphi$ 115-118, Ta (L.) 75, Ta (W.) 18-20, $\omega 1$ 20, $\omega 2$ 7-8, $\omega 3$ 25-28, \& 4-5, aa 15-23, ba 17-20, wa 37-50, ra 30, la 20-23, d 30-35, e 7-10, f 18-23, p 4-5, q 4-5, s 5-6, u 5, v 5, condylophore 12-15, claw 12-15; leg II: Tr 32-38, $p R$ 37-43, Fe 50-55, $v F$ 42-63, Ge 37-48, cG 27-35, mG 30-43, $\sigma$ 25-30, Ti 32-35, gT 30-37, hT 32-43, $\varphi$ 115-120, Ta (L.) 65-73, Ta (W.) 15-18, $\omega$ 17-23, ba 20-25, wa 42-58, ra 27-33, la 25-30, d 30-38, e 7-8, $f$ 15-18, $p 4, q 4, s$ 5-7, u 5, v5, condylophore 12-15, claw 11-13; leg III: Tr 37-39, sR 47-53, Fe 35-45, Ge 35, $n G$ 50-63, $\sigma$ 14-19, Ti 27-35, kT 55-60, $\varphi$ 112-133, Ta (L.) 82, Ta (W.) 12-13, w 37-40, $r$ 27-30, d 30-38, e 7-8, f 22-32, p 3-4, q 3-4, s 5-7, u 4-5, $v$ 4-5, condylophore 10-13, claw 1013; leg IV: Tr 37-48, Fe 42-50, $w F$ 42-55, Ge 42-45, Ti 35-43, $k T$ 40-60, $\varphi$ 102-113, Ta (L.) 87-95, Ta (W.) 12-13, w 32-43, r 15-18, d 37-40, e 7-8, f22-30, p 2-4, q 2-4, s 5, u 5, v 5, condylophore 12-13, claw 11-13; Fe, Ge and Ti IV with minute preapical process (Fig. 12). Tarsus IV with setae $w$ and $r$ spiniform (Figs. 12, 90).

Remarks. Our redescription shows minor differences between the Iranian specimens and previously published specimens of $T$. longior (by Fan and Zhang 2007). (1) Ratios: sci/sce 1.525-1.625; d1/d2 1.34-1.35 vs. sci/sce 2.1 (1.9-2.1); d1/d2 1.5
(1.5-1.9). (2) Dorsal setae of Iranian specimens are shorter than those of New Zealand specimens: $v i$ 82-87; ve 40-55; sci $182-195$; c1 32-38; c2 187-202; cp 125-138; d1 47-57; el 282-300; e2 207-212; f2 317-352; h1 295-350; h2 322-355; h3 262-300 vs. vi 100-107, ve 60-62, sci 238-248, c1 45-50, c2 263-280, cp 188-196, d1 67-88, el 413-421, f2 427-433, h1 408-425, h2 433-446, h3 369-385. (3) Ventral setae of Iranian specimens are shorter than those of New Zealand specimens: 1a 37-50, 3a 20-25, 4a 50-53, ad3 13-18, ad2 15-20, ad1 17-20, ps3 22-25, ps2 77-90, ps 1 200-228 vs. 1 a 58-60, 3a 31-33, 4a 77-87, ad2 32-35, ad1 31-38, ps2 129-139, Ps1 258-289. (4) Measurements of legs I-IV of Iranian specimens are smaller than those of the New Zealand specimens: Leg I: $v F$ 52-55, $\sigma 1$ 52-63, $\sigma 2$ 25-32, $m G$ 45-50, $\varphi$ 115-118, gT 25-38, hT 32-43, tarsus 75, aa 15-23, ba 17-20, ra 30, la 20-23; Leg II: $c G$ 27-35, mG 30-43, $\varphi$ 115-120, hT 32-43, tarsus 65-73, ba 20-25, wa 42-58, ra 27-33; Leg III: $n G$ 50-63, $\sigma$ 14-19, $\varphi$ 112-133, kT 55-60, w 37-40; Leg IV: $w F$ 42-55, $\varphi$ 102-113, tarsus $w 32-43$ vs. Leg I: $v F 65-66 ; \sigma 1$ 72-75, $\sigma 240-41, m G$ 59-60; $\varphi$ 139-144, gT 43-45, tarsus 109-113, a a 35-36, ba 36-38, ra 40-41, la 29-31; Leg II: cG 41-43, $m G$ 53-60; $\varphi$ 153-158, hT 45-52; tarsus 105-110, ba 36-38, wa 56-64, ra 38-44; Leg III: $n G$ 75-85, $\sigma 28-45, \varphi$ 155-166, $k T$ 77-83; $w$ 45-46; Leg IV: $w F$ 63-66; $\varphi$ 127-143, tarsus 138-139, w 56-59.

Material examined. Our specimens were collected from the soil and litter under a white willow tree, Salix alba L. (Salicaceae), in Kamar Basteh Forest Park, Tuyserkan region, Hamedan province, Iran $\left(34^{\circ} 35^{\prime} 58^{\prime \prime} \mathrm{N}, 48^{\circ} 13^{\prime} 39^{\prime \prime} \mathrm{E}\right.$; $34^{\circ} 35^{\prime} 59^{\prime \prime} \mathrm{N}$, $\left.48^{\circ} 26^{\prime} 38.8^{\prime \prime} \mathrm{E}\right)$. They were collected by F. Masoudian on June 1, 2015 and September 4, 2015. After the analysis, all specimens were deposited in the Collection of the Acarology Laboratory, University of Bu-Ali Sina, Hamedan, Iran.

\section{Tyrophagus similis Volgin, 1949: 387}

Diagnosis. Eyespots absent; supracoxal seta $(s c x)$ long, slender and with pectinations (40-50 $\mu \mathrm{m})$; ratio: $d 1 / c 10.75-1.03$; $d 1 / d 21.08-1.12$; $d 2 /$ c1 0.70-0.92; coxal plates II broadly triangular and with a well-developed apodeme near base of trochanter seta; tarsi I-II with cylindrical solenidia ( $\omega 1$ and $\omega$, respectively); spermathecal duct (35-45 long) very wide and long on its entire length with a long neck near spermathecal sac; tarsus IV with setae $w$ and $r$ spiniform. 
Female (Figs. 13-23, 61, 66, 71, 76, 81, 86, 91, 96; $n=8$ ). Idiosoma oval. Length of body, including gnathosoma, 613-730, excluding gnathosoma 525-630; width 312-338.

Dorsum (Figs. 13-15, 61, 66). Prodorsal shield punctate, with two pairs of setae ( $v i$ and $v e$ ) almost pentagonal in shape with lateral margins a slightly concave; 85-95 long, 100-118 wide between setae ve-ve. Eyespots absent (Figs. 13, 15, 61); basal lobe of Grandjean's organ with one large tooth and two small teeth, 17-20, 4-5 and 4 long, respectively (Fig. 14). Supracoxal seta scx pectinated and slender with four branches on each side (Figs. 13, 15, 66). All dorsal setae finely serrated. All opisthosomal setae whip-like except $c 1, d 1$ and $d 2$. Dorsal opisthosoma with three pairs of cupules ( $i a$, im and $i p$ ) and one pair of opisthosomal gland ( $g l a)$ at level of seta $e 1$; seta $c 1, d 1$ and $d 2$ are the shortest, whereas seta $h 2$ is the longest dorsal setae; length of dorsal setae: vi 88-105; ve 45-60; sci 195-218; sce 112-143; scx 37-50; c1 17-27; c2 190-208; cp 140-163; d1 13-28; d2 12-25; el 240-263; e2 195-250; f2 295-363; h1 320-350; h2 375-395. Distances: vi-vi 10-13; vi-ve 37-50; ve-ve 100-113; sce-sce 90-110; sci-sce 25-30; sci-sci 37-50; sce-ve 80-83; cl-cl 125-150; $c 1-c 2$ 42-58; $c 2-c 2$ 225-278; $c 2-c p$ 30-50; $c p-c p$ 275-338; c1-d1 50-63; d1-d1 75-93; d1-d2 87113; d1-e1 82-103; d2-d2 227-233; d2-gla 62-75; gla-gla 262-313; gla-el 62-83; e1-el 150-160; el-e2 125-150; e2-e2 282-350; e2-f2 45-50-; f2-f2 225-270; el-h1 150-175; h1-h1 110-130; h1-h2 50-68; h2-h2 85-113. Ratio: d1/cl 0.75$1.03 ; d 1 / d 2$ 1.08-1.12; $d 2 / c 1$ 0.70-0.92.

Gnathosoma (Figs. 16-17). Punctate; palp tarsus with a simple seta $(p t)$ and one solenidion ( $\omega$ ) 18-23 and 6-7 long, respectively; palp tibia with two simple setae ( $d 25-28$ and $l$ 18-21 long); Infracapitulum with one simple seta $(m)$ 30-38 long, palp coxa with one elcp setae 13-15 (Fig. 16); Chelicerae 95-110 long, cheliceral seta cha spinelike 8-10 long, movable and fixed digits with 4 teeth (Fig. 17). Distance: $m-m$ 19-23.

Venter (Figs. 18-19, 71, 76, 96). Coxal plates I divided with apodemes I anteriorly on each side with three nodules (Fig. 71); coxal plates II broadly triangular and with an well-developed apodeme near base of trochanter seta (Fig. 76); between coxae II and III with a pair of thin sclerotized sejugal apodemes, 63-65 long; coxal plates III-IV each with apodemes (Fig. 18); genital region (posterior to sejugal apodemes to coxae IV) with a pair of setae ( $g$ ) and genital folds (Fig. 18). Anal region with three pairs of adanal setae ( $a d 1-3)$ and three pairs of pseudanal setae ( $p s 1-3)$, seta ps 1 the longest anal setae (Fig. 18); a pair of cupule $(i h)$ at level base of seta $p s 2$. Copulatory opening (10-11 in diameter) located posterior to anal opening, Spermathecal duct (35-45 long) very wide along its entire length and join base of spermathecal sac and with a long neck (Figs. 19, 96); Length of ventral setae: $1 a$ 32-33, c3 25-43, 3a 15-23, 3b 35-43, 4a 37-50, g 15-23, ad3 12-18, ad2 15-18, adl 15-19, ps3 20-25, ps2 75-92, ps1 175-238, h3 225-303.

Legs (Figs. 20-23, 81, 86, 91). Leg I-II with cylindrical solenidion ( $\omega 1$ and $\omega$, respectively) (Figs. 21-22, 81, 86). Measurements of leg segments and setae as follows: leg I: $\operatorname{Tr} 35-50, p R$ 17-27, Fe 50-65, vF 43-50, Ge 37-48, cG 32-35, $m G$ 37-48, $\sigma 1$ 60-70, $\sigma 2$ 25-35, Ti 37-38, gT 2533, $h T$ 37-40, $\varphi$ 125-150, Ta (L.) 57-80, Ta (W.)

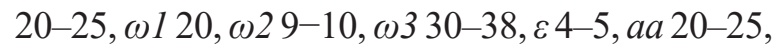
ba 18-25, wa 42-55, ra 32-45, la 22-30, d 35-43, e 8-10, f 18-25, p 4-5, q 4-5, s 7-8, u 5-6, v 5-6, condylophore 16-18, claw 15-16; leg II: Tr 37-45, $p R$ 25-30, Fe 50-63, vF 50-55, Ge 37-43, cG 27-38, $m G$ 37-50, $\sigma$ 27-30, Ti 30-32, gT 20-27, $h T 32-43, \varphi$ 132-150, Ta (L.) 62-75, Ta (W.) 17-20, w 20-25, ba 20-28, wa 42-50, ra 32-48, la 25-30, d 32-38, e 8-10, f 17-20, p 4-5, q 4-5, s 7-8, u 6-7, v 6-7, condylophore 12-15, claw 12-15; leg III: Tr 42-50, sR 38-50, Fe 32-45, Ge 37-45, nG 45-63, $\sigma$ 20-23, Ti 25-38, kT 37-45, $\varphi$ 120-152, Ta (L.) 62-85, Ta (W.) 12-15, w 35-45, r 25-38, $d$ 25-30, e 8-10, f 18-23, p 5, q 5, s 7-8, u 5-6, v 5-6, condylophore 13-15, claw 13-14; leg $I V: \operatorname{Tr}$ 38-45, Fe 45-55, wF 38-50, Ge 43-50, Ti 40-44, $k T$ 38-45, $\varphi$ 115-121, Ta (L.) 85-100, Ta (W.) 15-18, w 30-38, r 20-25, d 30-35, e 8-10, f28-35, $p 4, q 4, s 7-8, u 6, v 6$, condylophore 13-14, claw 13; Fe, Ge and Ti IV with minute preapical process (Fig. 23). Tarsus IV with setae $w$ and $r$ spiniform (Figs. 23, 91).

Remarks. Our redescription shows minor differences between the Iranian specimens and those from New Zealand (Fan and Zhang 2007): (1) The distance between dorsal seta $c 1-d 1$ in Iranian specimens is shorter than that of the New Zealand specimens (50-63 vs. 71-72); (2) The ratio $c 1-d 1$ l $d 1-e 1$ is 0.61 vs. 0.77-0.9; (3) Movable and fixed digits of chelicera have four teeth in Iranian specimens, as opposed to three teeth in New Zealand specimens. 

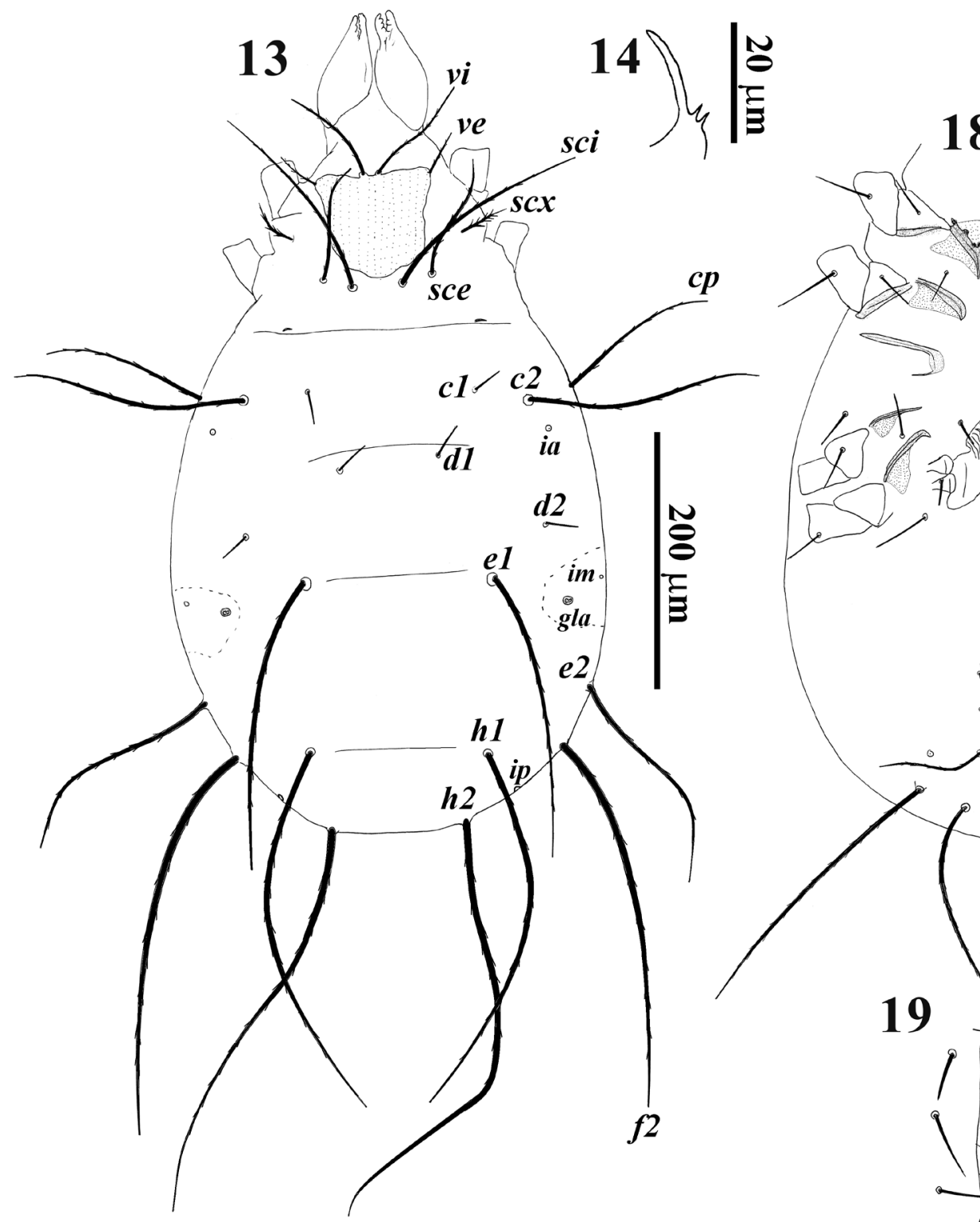


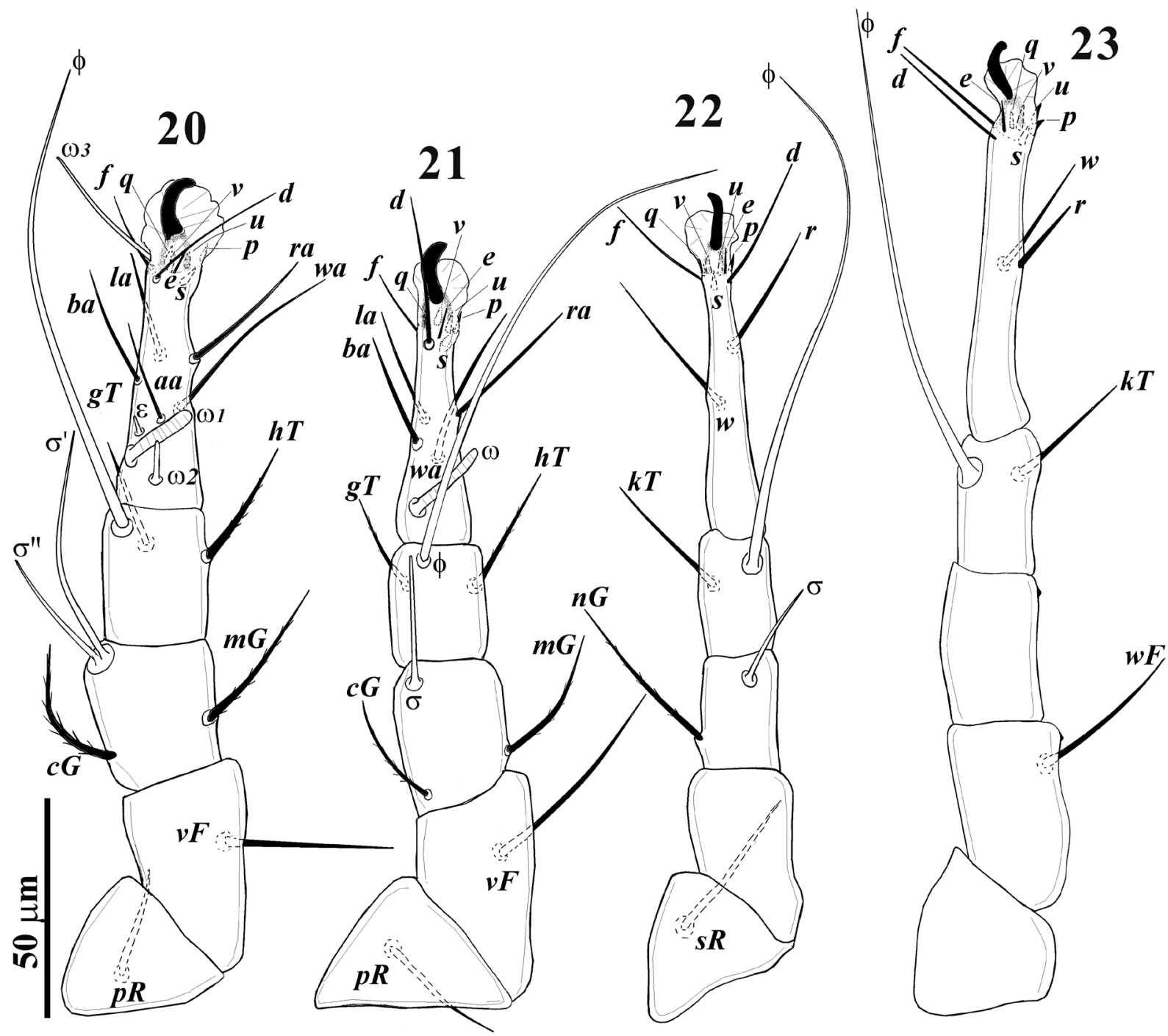

Figs. 20-23. T. similis Volgin, 1949 (female): 20. leg I; 21. leg II; 22. leg III; 23. leg IV.

Material examined. The specimens were collected from the forest soil and litter under a Persian walnut, Juglans regia L., (Juglandaceae), in Kamar Basteh Forest Park, Tuyserkan region, Hamedan province, Iran $\left(34^{\circ} 35^{\prime} 55^{\prime \prime} \mathrm{N}, 48^{\circ} 26^{\prime} 38^{\prime \prime} \mathrm{E}\right.$; $\left.34^{\circ} 35^{\prime} 40^{\prime \prime} \mathrm{N}, 48^{\circ} 26^{\prime} 38.7^{\prime \prime} \mathrm{E}\right)$. The specimens were collected by F. Masoudian on June 1, 2015 and September 4, 2015. All specimens have been deposited in the Collection of the Acarology Laboratory, University of Bu-Ali Sina, Hamedan, Iran.

\section{Tyrophagus vanheurni Oudemans, 1924: 326}

Diagnosis. Eyespots absent; supracoxal seta $s c x$ pectinated and slender with 4-5 branches on each side; ratio: $d 1 / c 11.62-2.19$; $d 1 / d 21.42-2.04$; $d 2 / c 1$ 1.07-1.13; coxal plates II broadly triangular, not reaching to beyond apex of apodeme II and with posterior margin sinuous shaped; spermathecal duct (45-50 long) cylindrical tube like and slightly widening toward base of spermathecal sac; aedeagus obviously with lateral arms supporting aedeagus turning inwards; tarsus I-II with cylindrical solenidion ( $\omega l$ and $\omega$, respectively); tarsus IV with setae $w$ and $r$ filiform.

Female (Figs. 24-35, 62, 67, 72, 77, 82, 87, $92,97 ; n=5)$. Idiosoma oval. Length of body including gnathosoma $633-700$, excluding gnathosoma 540-600; width 325-413.

Dorsum (Figs. 24-26, 62, 67). Prodorsal shield punctate, with two pairs of setae ( $v i$ and $v e$ ) almost pentagonal in shape with lateral margins a slightly concave; 88-100 long, 100-112 wide between setae ve-ve. Eyespots absent (Figs. 24, 62); basal lobe of Grandjean's organ with one large tooth and three small teeth, 18-20 and 7-8 long, 3 and 2-3 respectively (Fig. 25). Supracoxal seta $s c x$ pectinated and slender with 4-5 branches on each side (Figs. 26, 67). All dorsal setae finely serrated. All 
opisthosomal setae whip like except $c 1, d 1$ and $d 2$. Opisthosoma with three pairs of cupules ( $\mathrm{ia}, \mathrm{im}$ and $i p$ ) and one pair of opisthosomal gland $(\mathrm{gla})$ at level of seta $e 1$; Seta $c 1$ and $d 2$ are the shortest whereas seta $h 1-2$ is the longest dorsal setae; Length of dorsal setae: vi 100-112; ve 57-62; sci 217-237; sce 125-137; scx 30-40; c1 37-42; c2 222-237; cp 145-187; d1 60-92; d2 42-45; e1 295-320; e2 175-235; f2 337-347; h1 337-347; h2 337-362. Distances: vi-vi 13-17; vi-ve 42-45; ve-ve 102-112; sce-sce 110-120; sci-sce 27-30; sci-sci 42-50; sce-ve 80-85; cl-cl 137-152; c1-c2 50-75; c2-c2 235-300; $c 2-c p$ 37-50; $c p-c p$ $312-375 ; c 1-d 1$ 70-92; d1-d1 52-75; d1-d2 95130; d1-e1 95-117; d2-d2 237-300; d2-gla 57-77; gla-gla 255-342; gla-el 57-85; e1-el 125-177; e1-e2 75-125; el-f2 150-167; e2-e2 262-342; f2-f2 237-275; el-h1 125-157; h1-h1 107-137; h1-h2 52-57; h2-h2 70-100. Ratio: d1/cl 1.622.19; d1/d2 1.42-2.04; d2/c1 1.07-1.13.

Gnathosoma (Figs. 27-28). Punctate; palp tarsus with a simple seta $(p t)$ and one solenidion ( $\omega$ ) 12-15 and 6-7 long, respectively; palp tibia with two simple setae ( $d 27-28$ and $l 17-20$ long); Infracapitulum with one simple seta $(m)$ 37-42 long, palp coxa with one elcp setae 9-10 (Fig. 28); Chelicerae 100-105 long, cheliceral seta cha spinelike 7-8 long, movable and fixed digits with 3 teeth (Fig. 27). Distance: $m-m$ 19-20.

Venter (Figs. 29-31, 72, 77, 97). Coxal plates I divided with apodemes I anteriorly on each side with five nodules (Figs. 29, 72); coxal plates II broadly triangular, not reaching to beyond apex of apodeme II and with posterior margin sinuous shaped (Figs. 29, 77); between coxae II and III with a pair of thin sclerotized sejugal apodemes, 70-75 long; coxal plates III-IV each with apodemes (Fig. 29); genital region (posterior to sejugal apodemes to coxae IV) with a pair of setae ( $g$ ) and genital folds (Fig. 29). Anal region with three pairs of adanal setae (ad1-3) and three pairs of pseudanal setae (ps1-3), seta psl the longest anal setae (Fig. 29); a pair of cupule $(i h)$ at level base of seta $a d 1$. Copulatory opening (6-8 in diameter) located posterior to anal opening, Spermathecal duct (45-50 long) cylindrical tube like and slightly widening toward base of spermathecal sac (20-22 long) (Figs. 31, 97); Length of ventral setae: $1 a 50-57, c 340-42,3 a$ 25-30, 3b 42-57, 4a 57-67, g 20-25, ad3 15-18, ad2 22-30, ad1 22-27,ps3 22-27,ps2 75-102, ps 1 $157-215, h 3$ 262-277.

Legs (Figs. 32-35, 82, 87, 92). Leg I-II with cylindrical solenidion ( $\omega 1$ and $\omega$, respectively)
(Figs. 32-33, 82, 87). Measurements of leg segments and setae as follows: Leg I: Tr 37-52, pR 37-42, Fe 50-60, vF 50-62, Ge 37-45, cG 42-45, $m G$ 42-55, $\sigma 1$ 65-70, $\sigma 2$ 30-32, Ti 35-42, gT 32-40, hT 42-45, $\varphi$ 115-140, Ta (L.) 87-89, Ta (W.) 20-27, $\omega 1$ 22-25, $\omega 2$ 10-11, $\omega 3$ 27-32, \& 6-7, a a 25-27, ba 18-22, wa 38-50, ra 29-35, la 28-31, $d$ 32-38, e 8-10, f 18-20, $p$ 4-5, q 4-5, s 7-8, u 5-6, v 5-6, condylophore 17-18, claw 15; Leg II: Tr 37-50, $p R$ 42-52, Fe 50-60, vF 57-75, Ge 37-45, $c G$ 32-42, $m G$ 47-50, $\sigma$ 30-32, Ti 32-42, gT 37-40, hT 42-50, $\varphi$ 120-145, Ta (L.) 80-82, Ta (W.) 17-22, $\omega$ 25-30, ba 25-30, wa 47-57, ra 35-40, la 25-30, d 40-47, e 8-12, f22-25, p 4-5, $q$ 4-5, s 7-8, u 6-7, v 6-7, condylophore 15-18, claw 12-15; Leg III: Tr 37-45, sR 50-60, Fe 37-50, Ge 37-42, $n G$ 50-62, $\sigma 27-30$, Ti 30-42, kT 57-62, $\varphi$ 135-142, Ta (L.) 87-90, Ta (W.) 15-17, w 40-42, $r 30, d 32-37, e$ 7-10, f27-32, $p 4-5,4-q 5, s$ 6-8, $u$ 5-7, $v$ 5-7, condylophore 12-16, claw 12-15; Leg IV: $\operatorname{Tr} 45-50$, Fe 45-52, $w F$ 50-65, Ge 37-47, Ti 35-42, kT 50-62, $\varphi$ 125-137, Ta (L.) 100-107, Ta (W.) 12-15, w 40-42, r 20-22, d 35-45, e 8-9, f35-37, $p$ 3-4, q 3-4, s 7-8, u 5-7, v 5-7, condylophore 12-17, claw 12-13; Ge and Ti IV with minute preapical process (Fig. 32). Tarsus IV with seta $r$ filiform (Fig. 92).

Male (Figs. 36-47, 63, 68, 73, 78, 83, 88, 93, 99-100; $n=3$ ). Idiosoma oval, length of body including gnathosoma 552-565, excluding gnathosoma 467-475; width 300-320.

Dorsum (Figs. 36-38, 63, 68). Prodorsal shield punctate, with two pairs of seta ( $v i$ and $v e$ ) nearly pentagonal in shape with lateral margins slightly concave; 85-88 long, 90-95 wide between setae ve-ve. Eyespots absent (Figs. 36, 63); Basal lobe of Grandjean's organ with one large tooth and one small teeth, 17-18 and 6-7 long, respectively (Fig. 38). Supracoxal seta $s c x$ pectinated with four branches on each side (Figs. 37, 68). All dorsal setae finely serrated. All opisthosomal setae whip like except $c 1, d 1$ and $d 2$. Opisthosoma with three pairs of cupules ( $\mathrm{ia}$, im and ip) and one pair of opisthosomal glands ( $g l a)$ at level of seta e1; Setae $c l$ and $d 2$ the shortest and seta $f 2$ and $h 2$ the longest dorsal setae; Length of dorsal setae: vi 95-100; ve 44-50; sci 195-201; sce 120-124; scx 34-37; c1 35-37; c2 214-218; cp 94-97; d1 51-55; d2 39-42; el 321-326; e2 180-187; f2 356-365; h1 320-325; h2 360-364. Distances: vi-vi 10-12; vi-ve 33-35; ve-ve 90-93; sce-sce 95-100; sci-sce 20-24; sci-sci 30-35; c1-c1 120-125; c1-c2 51-54; c2-c2 220-225; c2-cp 25-30; $c p-c p$ 277-280; c1-d1 


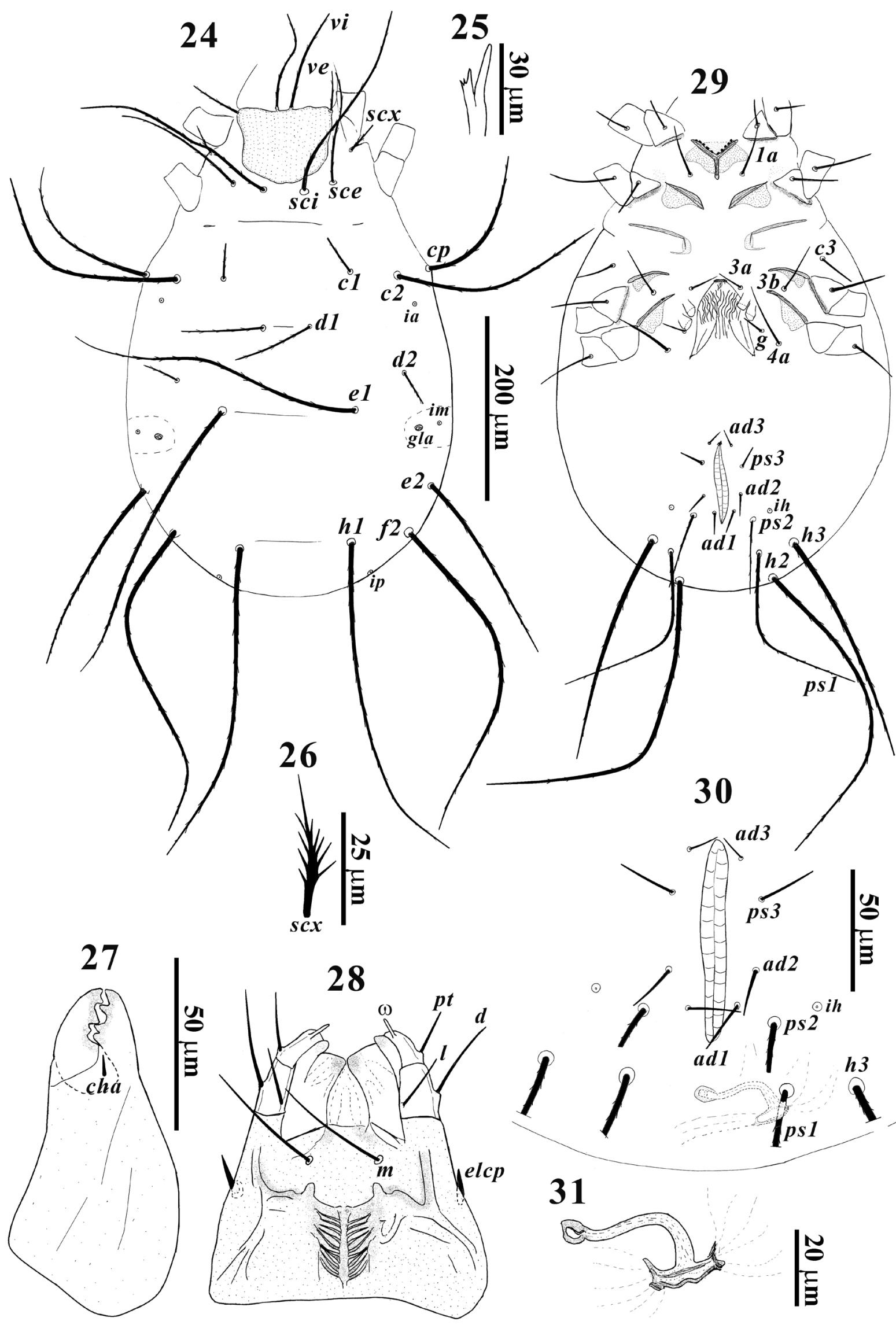

Figs. 24-31. T. vanheurni Oudemans, 1924 (female): 24. dorsal view; 25. Grandjean's organ; 26. supracoxal seta (scx); 27. chelicera; 28. gnathosoma; 29. ventral view; 30. anal region; 31. spermatheca. 


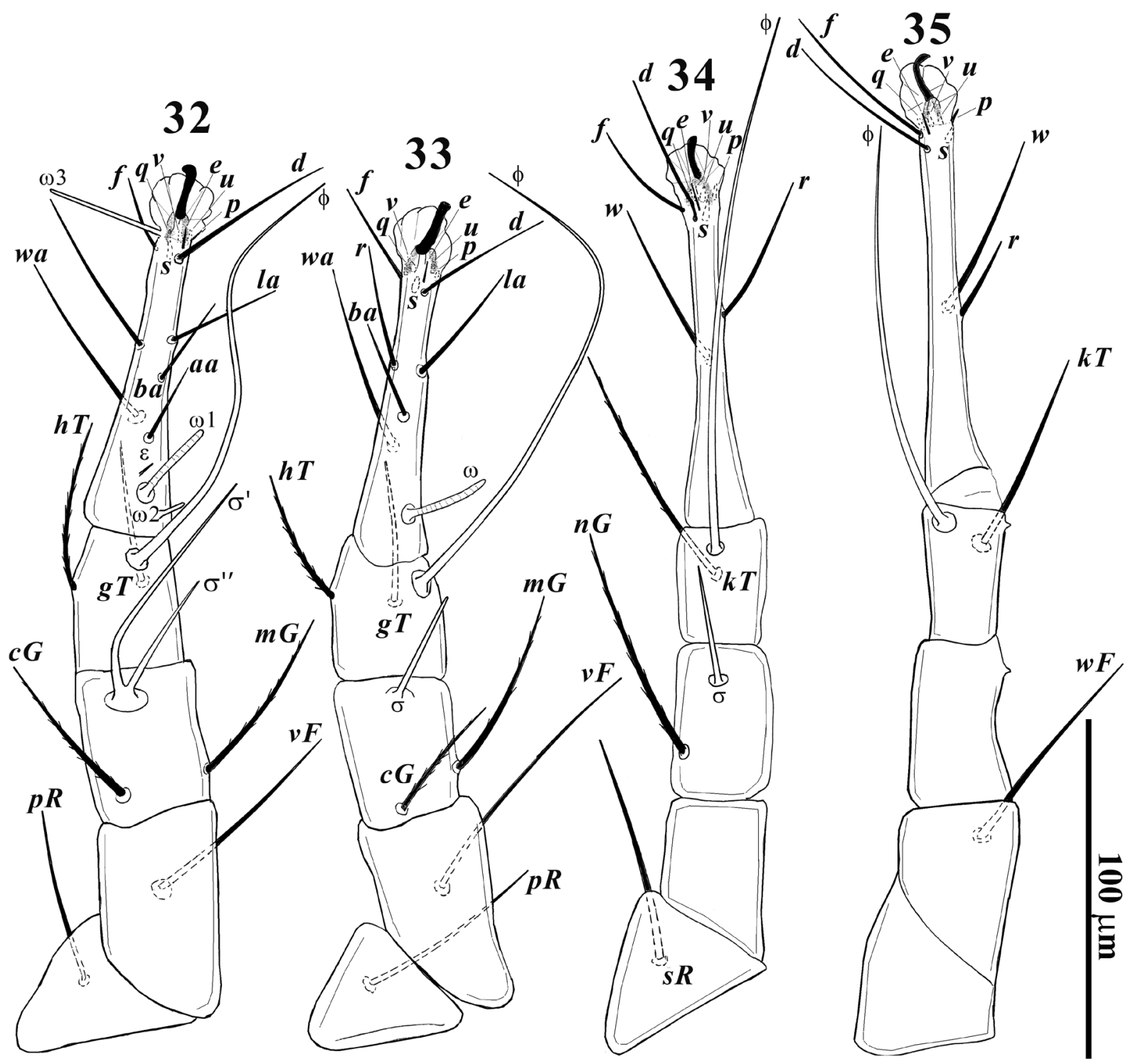

Figs. 32-35. T. vanheurni Oudemans, 1924 (female): 32. leg I; 33. leg II; 34. leg III; 35. leg IV.

58-62; d1-d1 48-50; d1-el 85-88; d1-d2 90-92; d2-d2 215-217; d2-gla 48-50; gla-gla 220-225; e1-gla 55-60; e1-el 115-120; e1-e2 84-87; e2-e2 220-225; f2-f2 180-185; el-h1120-125; h1-h1 85-87; h1-h2 48-52; h2-h2 55-60.

Gnathosoma (Figs. 39-40). Punctate; palp tarsus with a simple seta $(p t)$ and one solenidion ( $\omega$ ) 13-14 and 6-7 long, respectively; palp tibia with two simple setae ( $d 18-20$ and $l 15-16$ long); infracapitulum with one simple seta $(m)$ 32-35 long, distance: $m-m$ 19-21; Palp coxa with one elcp setae 7-8 (Fig. 40); chelicerae 91-95 long, cheliceral seta cha spine like 7-8 long, movable and fixed digits with 3 teeth (Fig. 39).

Venter (Figs. 41-43, 73, 78). Coxal plates I divided with apodemes I anteriorly on each side with four nodules (Figs. 41, 73); coxal plates II broadly triangular, not reaching to beyond apex of apodeme II and with posterior margin sinuous shaped (Figs. 41, 78); between coxae II and III with a pair of thin sclerotized sejugal apodemes, 60-65 long; Coxal plates III-IV each with apodemes (Fig. 41); genital region (between coxae IV) with a pair of setae $(g)$; aedeagus 43-45 long and obviously with lateral arms supporting aedeagus turning inwards (Figs. 42, 99-100). Anal region with three pairs of pseudanal setae ( $p s 1-3$ ), seta $p s 1$ and $p s 3$ the longest and the shortest anal setae respectively, a pair of anal suckers 28-30 and a pair of anal discs 4-5 in diameter (Figs. 43, 100); Length of ventral setae: $1 a 33-35, c 340,3 a 17-19$, 3b 35-37, 4a 60, g 20-24, ps3 18-19, ps 2 53-55, ps1 190-200, h3 280-288.

Legs (Figs. 44-47, 83, 88, 93). Solenidion $\omega 1$ and $\omega$ of legs I-II cylindrical solenidion ( $\omega 1$ and $\omega$, respectively) (Figs. 44-45, 83, 88). Measure- 


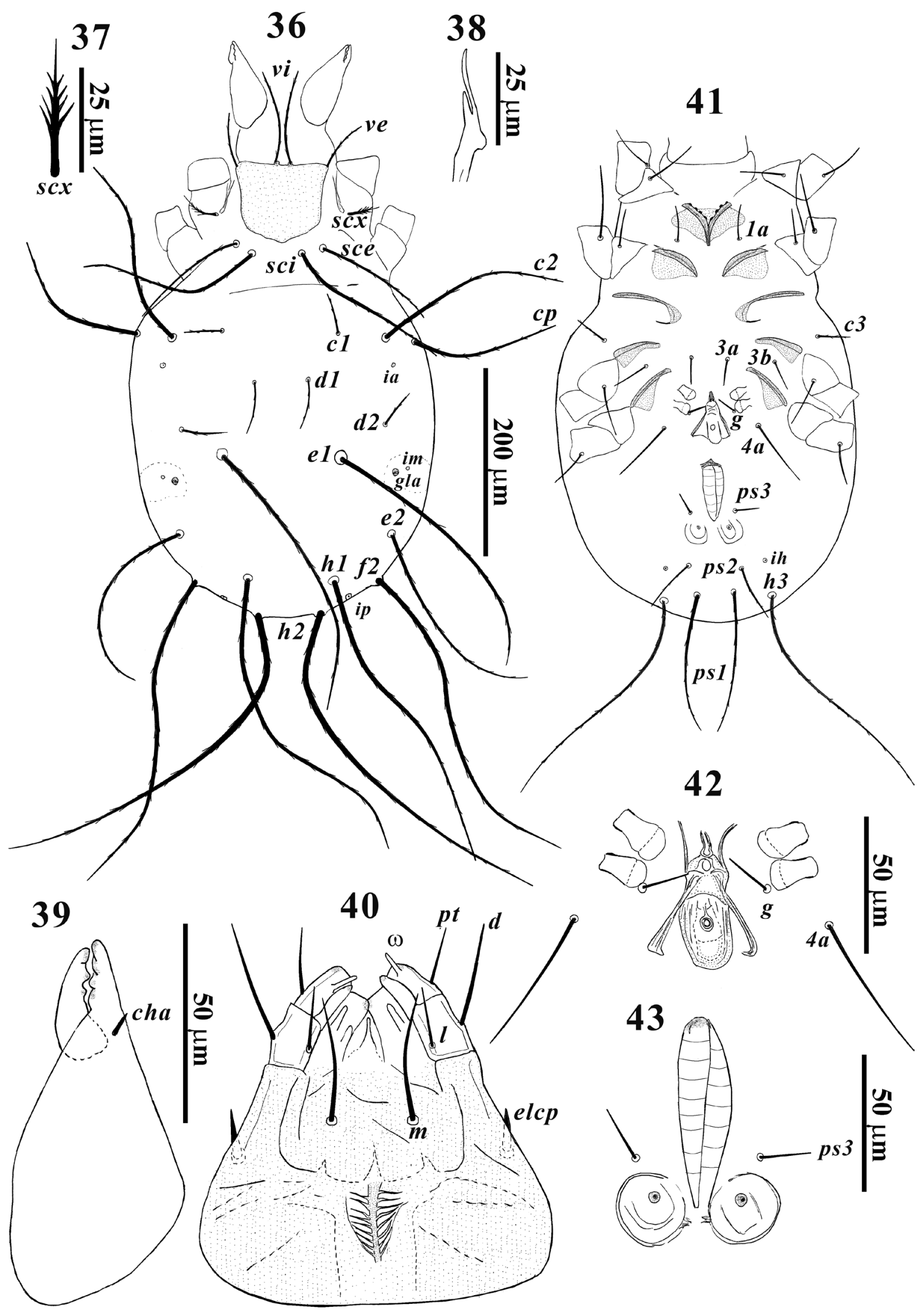

Figs. 36-43. T. vanheurni Oudemans, 1924 (male): 36. dorsal view; 37. supracoxal seta (scx); 38. Grandjean's organ; 39. chelicera; 40. gnathosoma; 41. ventral view; 42. aedeagus; 43. anal region. 


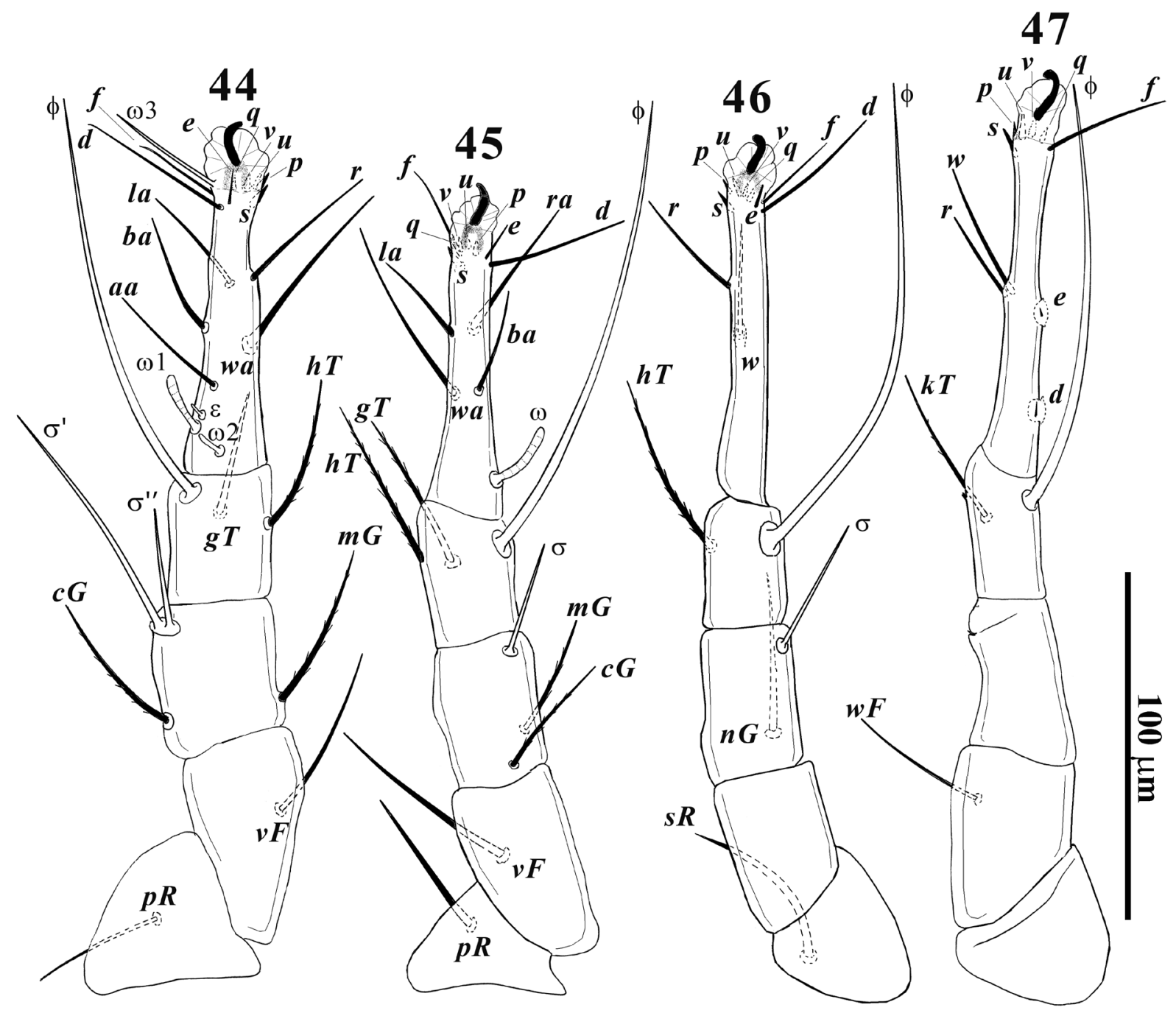

Figs. 44-47. T. vanheurni Oudemans, 1924 (male): 44. leg I; 45. leg II; 46. leg III; 47. leg IV.

ments of leg segments and setae as follows: leg I: $\operatorname{Tr} 40-42, p R$ 35-37, Fe 57, $v F$ 45-50, Ge 42-45, $c G$ 35-37, $m G$ 45-49, $\sigma 1$ 60-62, $\sigma 2$ 28-30, Ti 35-38, gT 32-33, hT 40-41, $\varphi$ 115-117, Ta (L.) 78-80, Ta (W.) 22-25; $\omega 1$ 20, $\omega 2$ 7-8, $\omega 3$ 29-30, $\varepsilon$ 5, a a 25-27, ba 20-23, wa 48-51, ra 38-41, la 30, d 37-38, e 11-13 f 18-20, p 3, q 3, s 6-7, u 5, $v$ 5, condylophore 17-18, claw 15; leg II: $\operatorname{Tr} 40-42$, $p R$ 40-43, Fe 38-52, vF 50-55, Ge 35-38, cG 29-32, $m G$ 42-45, $\sigma$ 27, Ti 34-37, gT 29-30, hT 35-37, $\varphi$ 110-115, Ta (L.) 70-75, Ta (W.) 20, $\omega$ 20, ba 28-31, wa 34-35, ra 40, la 24-26, d 34-38, $e$ 10, f20-23, p 3-4, q 3-4, s 7-8, u 5, v 5, condylophore 17-18, claw 14-15; leg III: Tr 38-41, sR 48-52, Fe 39-44, Ge 37-39, nG 52, $\sigma$ 30, Ti 35-38, kT 54-58, $\varphi$ 120-125, Ta (L.) 90-100, Ta (W.) 15, $w$ 44-46, r 34-37, d 42-45, e 10, f28-31, p 4, q4, $s$ 6-7, u 5, v 5, condylophore 14-16, claw 12-13; leg IV: Tr 42-45, Fe 50, $w F$ 40-41, Ge 36-38, Ti 35-37, kT 40-45, $\varphi$ 108-115, Ta (L.) 85, Ta (W.)
14-15, w 40-42, r 11-12, d 2-3, e 2-3, f 35-37, s 7-8, $p$ 4-5, q4-5, u 5-6, v5-6, condylophore 12-13, claw 12-13. Tarsus IV with two suckers (seta $d$ on proximal and seta $e$ on distal sucker), distance between base of seta $d$ and proximal segment of tarsus 19-20, $e-d$ 24-25, $e-f 38-40$ (Figs. 47, 93). Tarsus IV with seta $r$ filiform (Fig. 92).

Remarks. Our specimens have minor differences when compared to those from New Zealand (Fan and Zhang 2007). (1) Female pseudanal seta ps2 (75-102 long) is shorter than that of the New Zealand specimens (126-167 long). (2) Genual solenidia I-III of female specimens are longer than those of New Zealand specimens $(\sigma 165-70, \sigma 2$ $30-32$ vs. $\sigma 138-48, \sigma 218-24 ; \sigma 30-32$ vs. $\sigma 16-22$; $\sigma 27-30$ vs. $\sigma$ 13-16, respectively). (3) Dorsal setae of Iranian male specimens are shorter or longer than those of New Zealand specimens: $c p$ 94-97; $d 1$ 51-55 vs. $c p 135-152$; $d 1$ 68-110 and d2 39-42; el 321-326; f2 356-365; h1 320-325; 


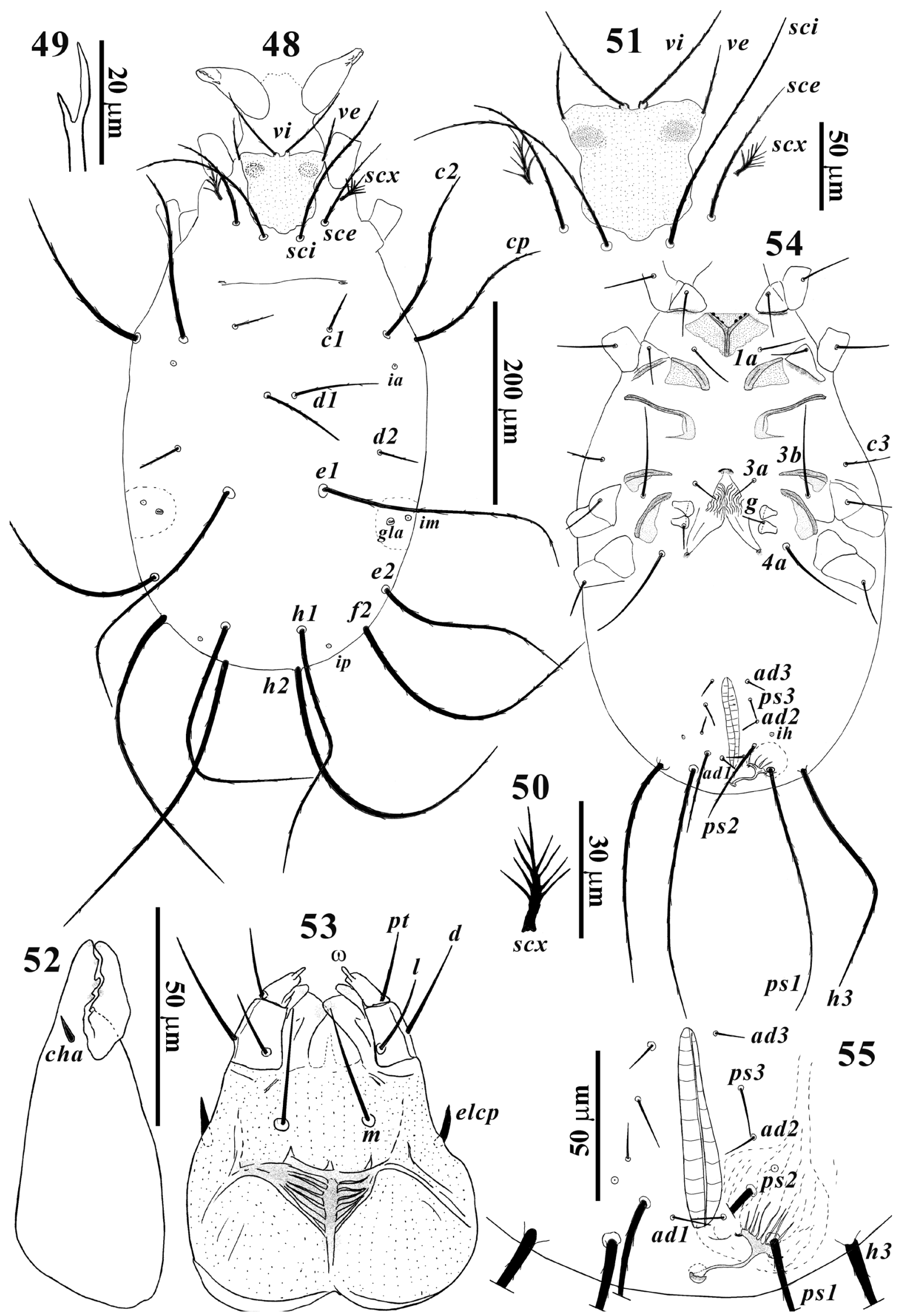

Figs. 48-55. T. neiswanderi Johnston and Bruce, 1965 (female): 48. dorsal view; 49. Grandjean's organ; 50. supracoxal seta (scx); 51. prodorsal shield; 52. chelicera; 53. gnathosoma; 54. ventral view; 55. anal region. 


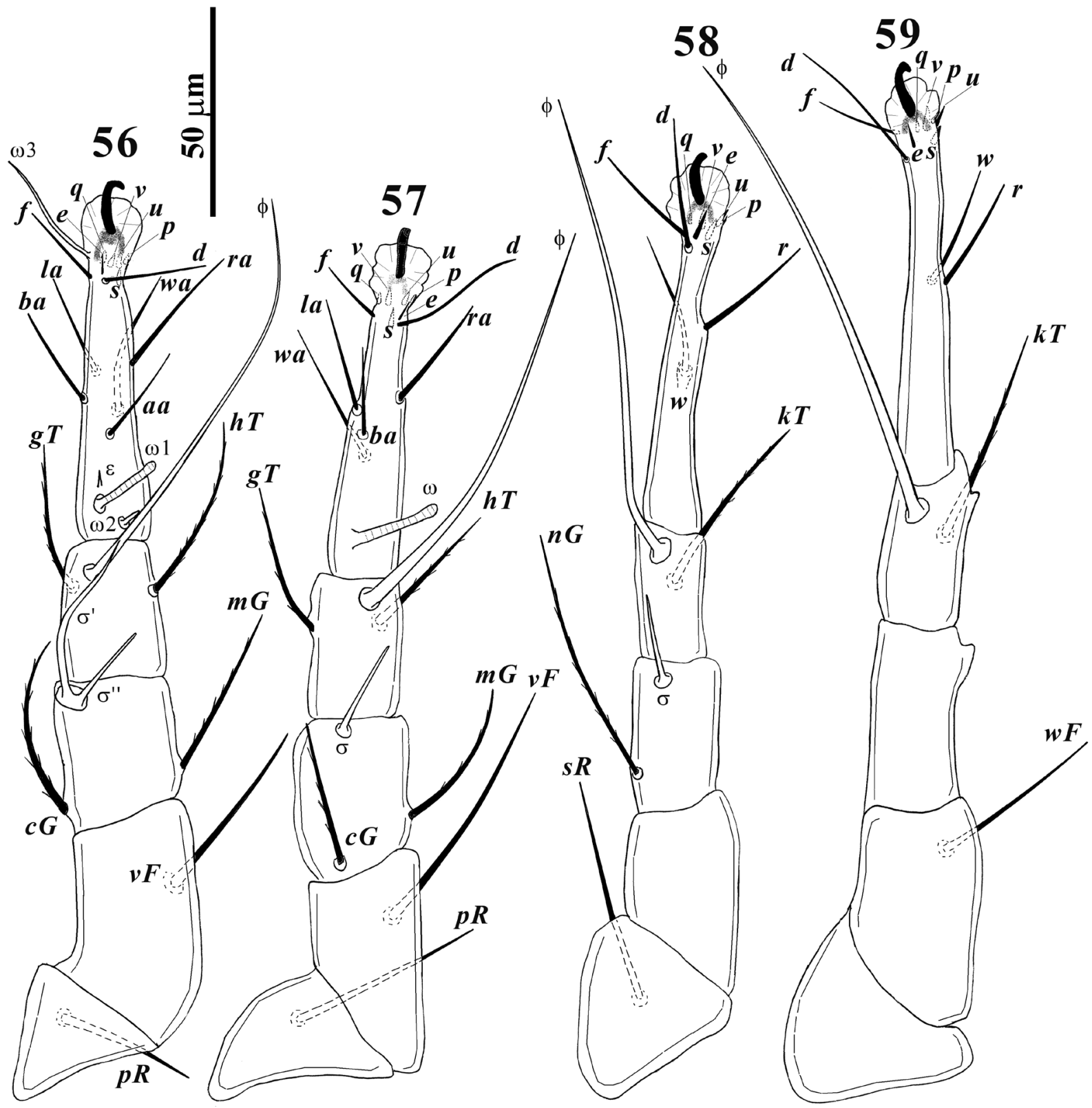

Figs. 56-59. T. neiswanderi Johnston and Bruce, 1965 (female): 56. leg I; 57. leg II; 58. leg III; 59. leg IV.

h2 360-364 vs. d2 23-28; el 222-278; f2 226-299; h1 247-288; h2 331-331, respectively. (4) Legs setae of Iranian male specimens are longer: leg $I$ ( $\sigma 1$ 60-62, $\sigma 228-30$ vs. $\sigma 128-40$, , 2 13-18; leg II: $\sigma 27$ vs. $\sigma 13-17$; leg III: $\sigma 30, w$ 44-46, $r$ 34-37 vs. $\sigma 12-20, w 23-28, r 20-25 ; \operatorname{leg} I V: w 40-42$ vs. w 22-32).

Material examined. The specimens were collected from soil and litter under a narrow-leafed ash tree, Fraxinus angustifolia Vahl (Oleaceae), in Giyan, Nahavand region, Hamedan province, Iran $\left(34^{\circ} 08^{\prime} 44^{\prime \prime} \mathrm{N}, 48^{\circ} 13^{\prime} 23^{\prime \prime} \mathrm{E}\right)$, by F. Masoudian on August 19, 2015. All specimens have been deposited in the Collection of the Acarology Laboratory, University of Bu-Ali Sina, Hamedan, Iran.
Tyrophagus neiswanderi Johnston and Bruce, 1965: 3

Diagnosis. Eyespots present; supracoxal seta $s c x$ pectinated and slender with 4 branches on each side; ratio: $d 1 / c 1$ 2.23-2.28; $d 1 / d 2$ 2.28; $d 2 / c 1$ 0.97-1.00; coxal plates II broadly triangular, not reaching to beyond apex of apodeme II and with posterior margin sinuous shaped; spermathecal duct (28-35 long) thin tube; tarsus I-II with slender and cylindrical shape solenidion $(\omega 1$ and $\omega$, respectively); tarsus IV with setae $w$ and $r$ filiform.

Female (Figs. 48-59, 64, 69, 84, 89, 94, 98; $\mathrm{n}=4$ ). Idiosoma oval. Length of body including gnathosoma 500-575, excluding gnathosoma 425-500; width 240-280. 

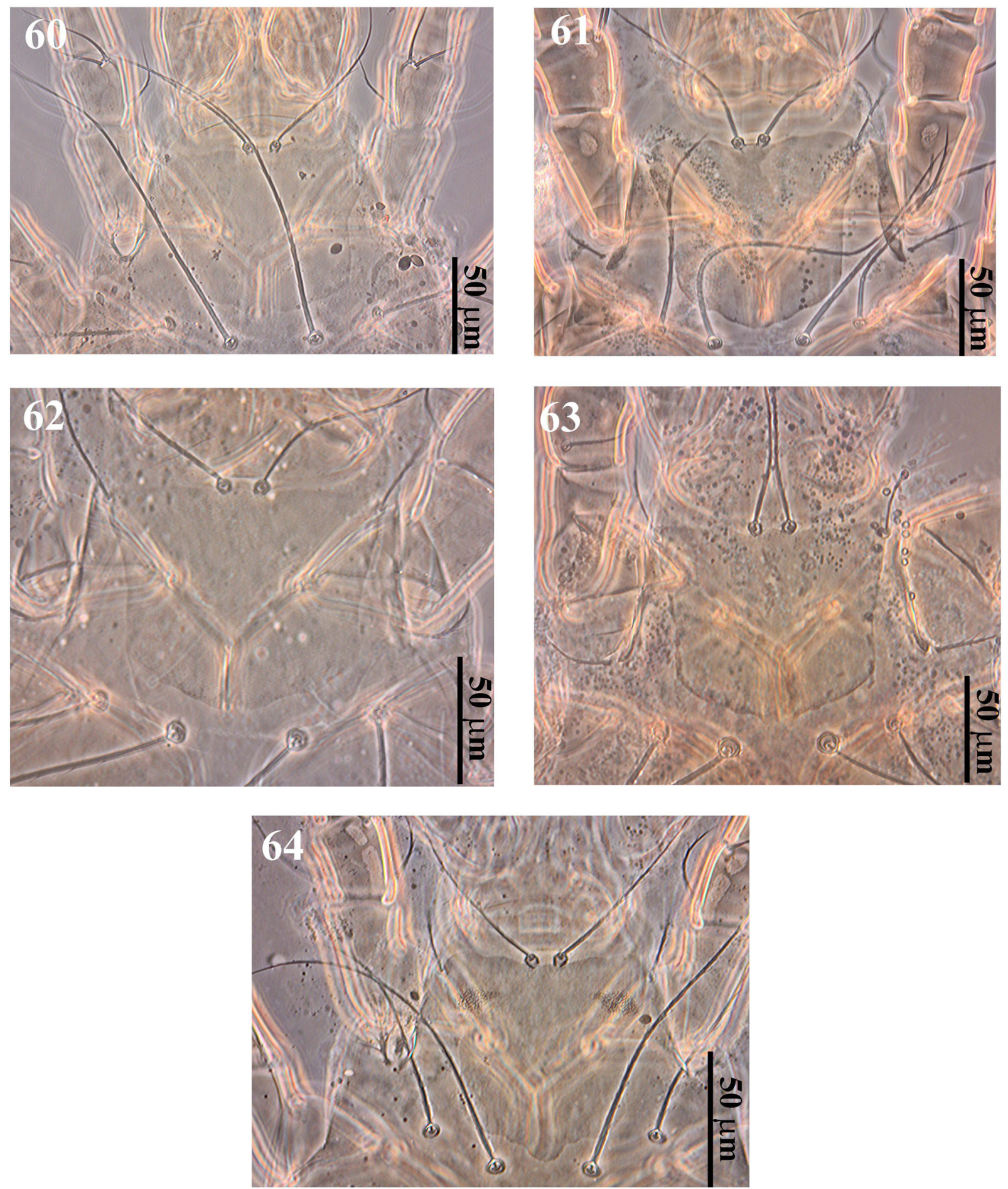

Figs. 60-64. Prodoral shields: 60. T. longior (Gervais, 1844) (female); 61. T. similis Volgin, 1949 (female); 62. T. vanheurni Oudemans, 1924 (female); 63. T. vanheurni Oudemans, 1924 (male); 64. T. neiswanderi Johnston and Bruce, 1965 (female).

Dorsum (Figs. 48-51, 64, 69). Prodorsal shield punctate, with two pairs of setae ( $v i$ and $v e$ ) almost pentagonal in shape with lateral margins a slightly concave; 75-78 long, 83-88 wide between setae ve-ve. Eyespots present and 15-18 in diameter (Figs. 48, 51, 64); basal lobe of Grandjean's organ with one large tooth and one small teeth, 13-15 and 5-6 long respectively (Fig. 49). Supracoxal seta $s c x$ pectinated and slender with 4 branches on each side (Figs. 48, 50-51, 69). All dorsal setae finely serrated. All opisthosomal setae whip like except $c 1, d 1$ and $d 2$. Opisthosoma with three pairs 

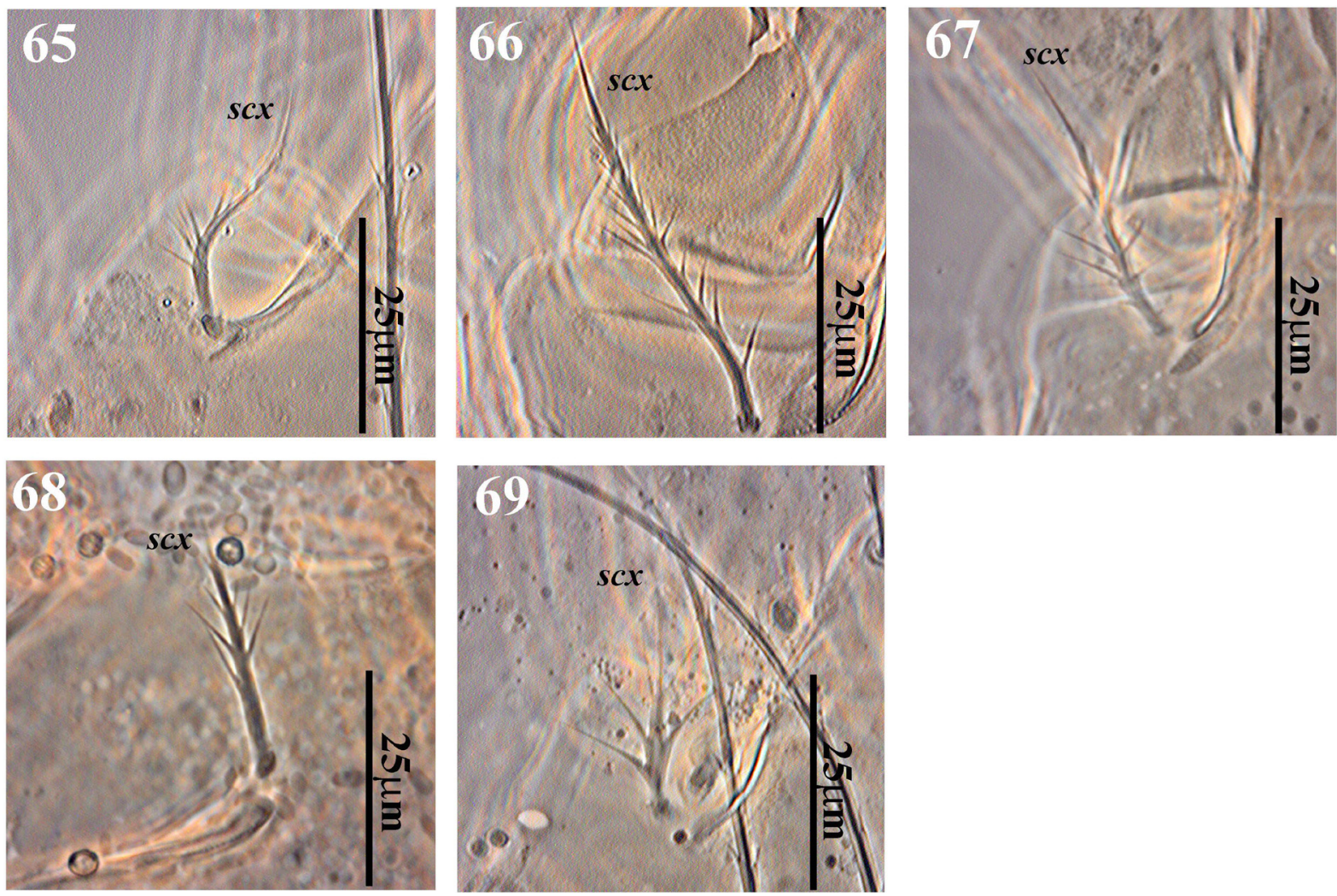

Figs. 65-69. Supracoxal setae (scx): 65. T. longior (Gervais, 1844) (female); 66. T. similis Volgin, 1949 (female); 67. T. vanheurni Oudemans, 1924 (female); 68. T. vanheurni Oudemans, 1924 (male); 69. T. neiswanderi Johnston and Bruce, 1965 (female).

of cupules ( $\mathrm{ia}$, im and ip) and one pair of opisthosomal gland ( $g l a)$ at level of seta $e 1$; seta $c 1$ and $d 2$ are the shortest whereas seta $h 2$ the longest dorsal setae; length of dorsal setae: vi 74-76; ve 40-43; sci 145-165; sce 88-100; scx 28-33; c1 35-38; c2 165-175; cp 145-150; d1 80-85; d2 35-37; e1 280-300; e2 185-210; f2 288-300; h1 275-288; h2 301-306. Distances: vi-vi 12-13; vi-ve 33-35; ve-ve 80-83; sce-sce 75-80; sci-sce 25-28; sci-sci 35-38; sce-ve 58-65; c1-cl 86-95; $c 1-c 2$ 40-50; $c 2-c 2$ 168-190; $c 2-c p$ 25-37; $c p-c p$ 230-270; c1-d1 50-65; d1-d1 27-30; d1-d2 80$100 ; d 1-e 1$ 80-100; d2-d2 180-200; d2-gla 5063; gla-gla 180-220; gla-el 50-62; e1-el 78-95; e1-e2 85-100; e1-f2 100-125; e2-e2 180-220; f2-f2 180-200; e1-h1 100-125; h1-h1 60-78; h1-h2 35-38; h2-h2 53-70. Ratio: d1/cl 2.232.28; d1/d2 2.28; d2/c1 0.97-1.00.

Gnathosoma (Figs. 52-53). Punctate; palp tarsus with a simple seta $(p t)$ and one solenidion ( $\omega$ ) 12-13 and 5 long, respectively; palp tibia with two simple setae ( $d 21-27$ and $l 17-19$ long); infracapitulum with one simple seta $(m)$ 30-35 long, distance: $m-m$ 20; palp coxa with one elcp setae 12-13 (Fig. 53); chelicerae 80-85 long, cheliceral seta cha spine-like 7-8 long, movable and fixed digits with 3 teeth (Fig. 52).

Venter (Figs. 54-55, 74, 79, 98). Coxal plates I divided with apodemes I anteriorly on each side with three nodules (Fig. 54, 74); coxal plates II broadly triangular, not reaching to beyond apex of apodeme II and with posterior margin sinuous shaped (Fig. 54, 79); between coxae II and III with a pair of thin sclerotized sejugal apodemes, 57-62 long; coxal plates III-IV each with apodemes (Fig. 54); genital region (posterior to sejugal apodemes to coxae IV) with a pair of setae ( $g$ ) and genital folds (Fig. 54). Anal region with three pairs of adanal setae (ad1-3) and three pairs of pseudanal setae ( $p s 1-3)$, seta $p s 1$ the longest anal setae (Fig. 54); a pair of cupule (ih) at level base of seta ad1. Copulatory opening (5-6 in diameter) located posterior to anal opening, spermathecal duct (28-35 long) thin tube, spermathecal sac (15-18 long) (Figs. 55, 98); Length of ventral setae: $1 a$ 45-48, c3 32-35, 3a 18-25, 3b 83-88, 4a 75-78, g 15-18, ad3 10-13, ad2 12-15, ad1 15-18, ps3 18-21, ps2 80-92, ps1 188-200, h3 210-238.

Legs (Figs. 56-59, 84, 89, 94). Leg I-II with slender and cylindrical shape solenidion $(\omega 1$ and 

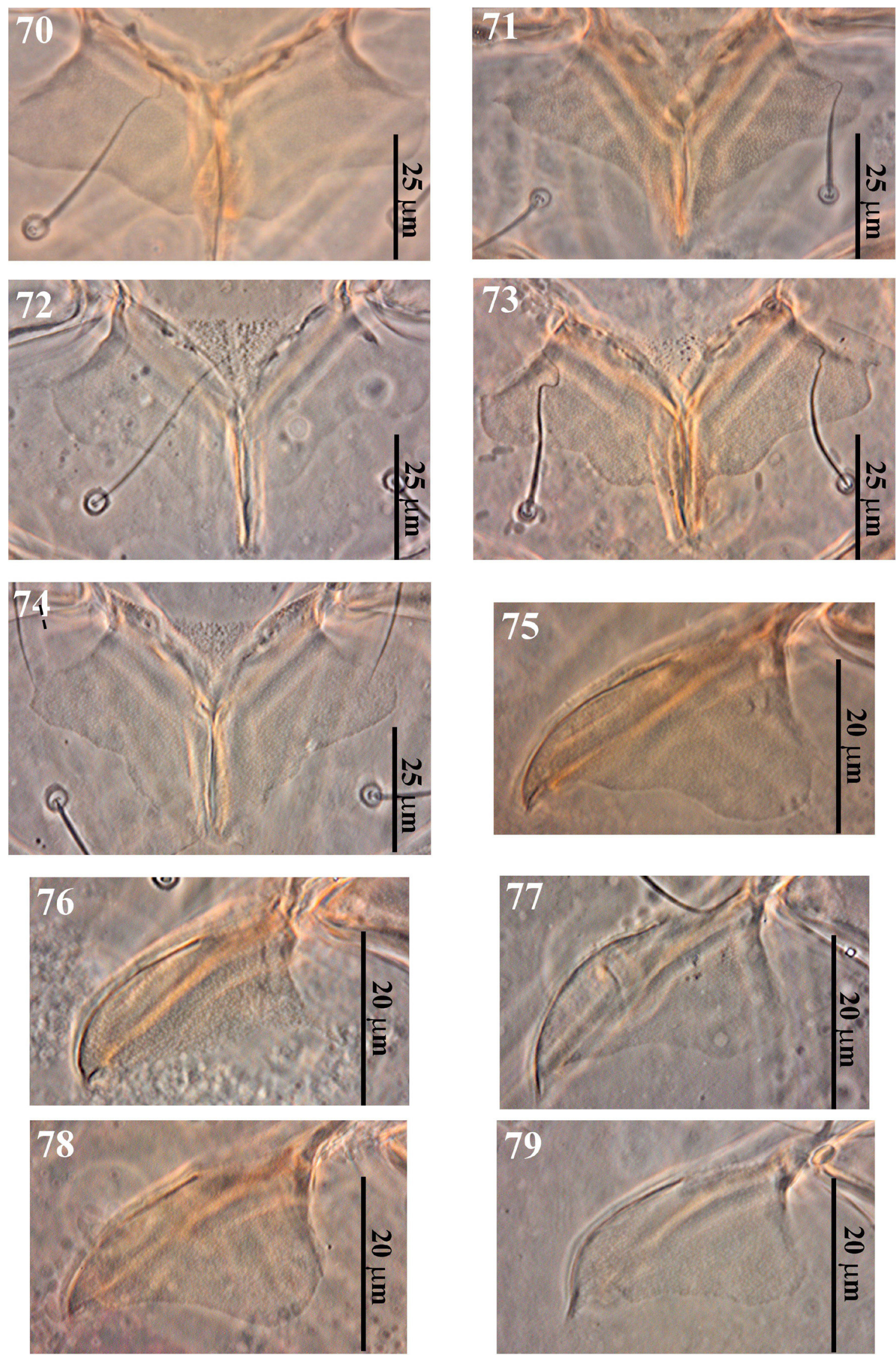

Figs. 70-79. Coxae I-II, respectively: 70, 75. T. longior (Gervais, 1844) (female); 71, 76. T. similis Volgin, 1949 (female); 72, 77. T. vanheurni Oudemans, 1924 (female); 73, 78. T. vanheurni Oudemans, 1924 (male); 74, 79. T. neiswanderi Johnston and Bruce, 1965 (female). 

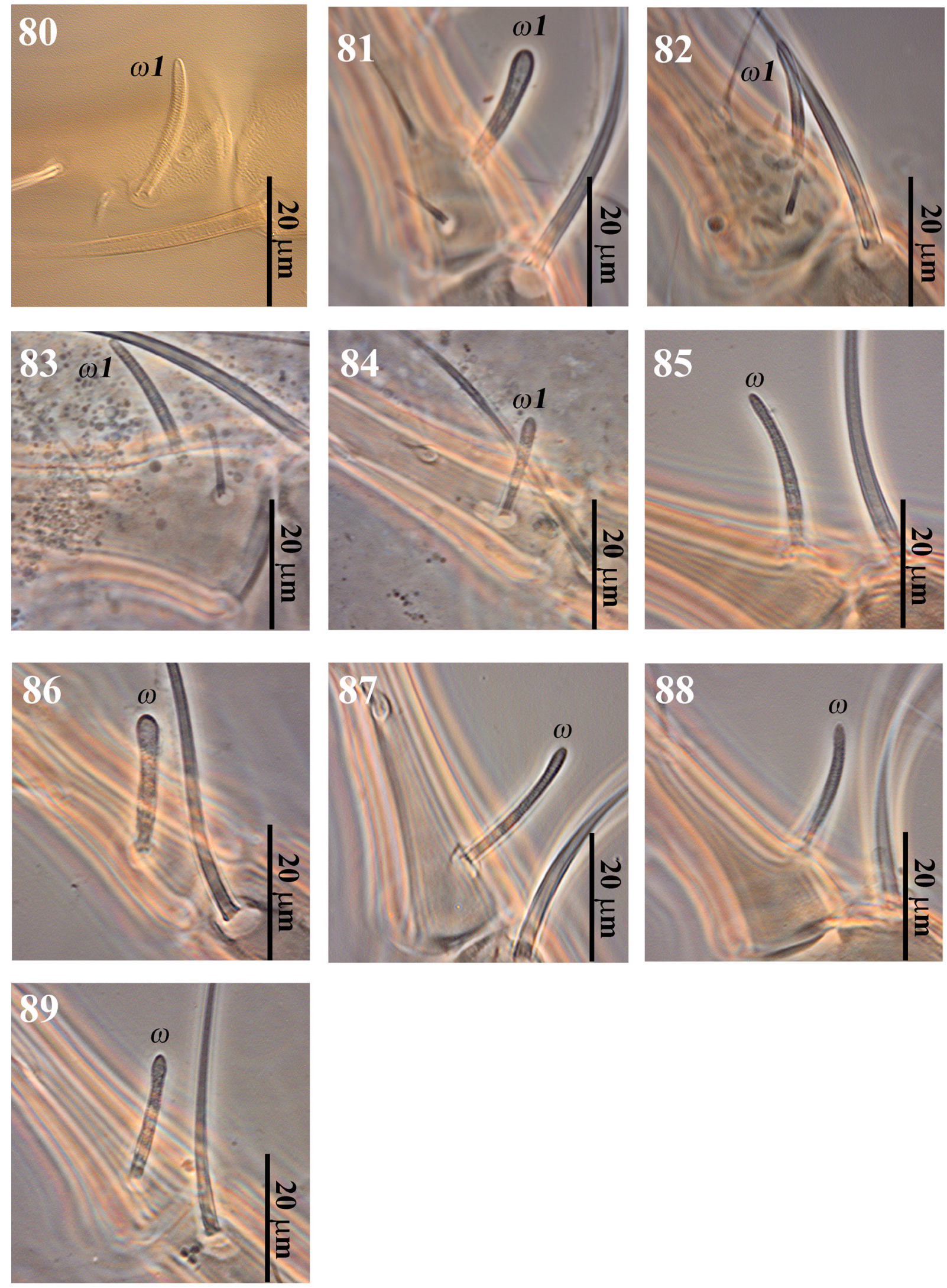

Figs. 80-89. Solenidion $\omega 1$ on tarsus I and Solenidion $\omega$ on tarsus II (female), respectively: 80, 85. T. longior (Gervais, 1844) (female); 81, 86. T. similis Volgin, 1949 (female); 82, 87. T. vanheurni Oudemans, 1924 (female); 83, 88. T. vanheurni Oudemans, 1924 (male); 84, 89. T. neiswanderi Johnston and Bruce, 1965 (female). 

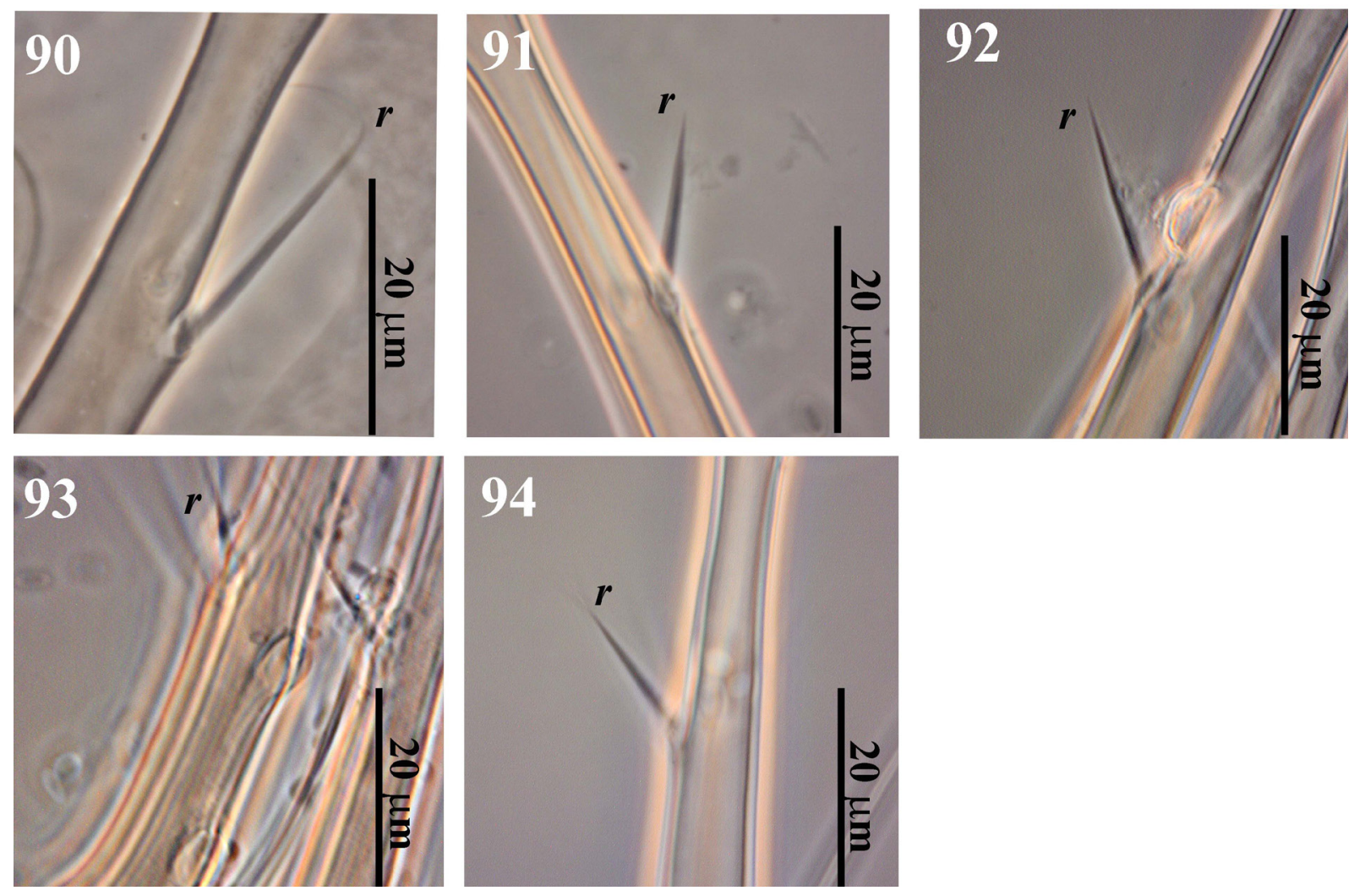

Figs. 90-94. Seta $r$ on tarsus IV: 90. T. longior (Gervais, 1844) (female); 91. T. similis Volgin, 1949 (female). 92. T. vanheurni Oudemans, 1924 (female); 93. T. vanheurni Oudemans, 1924 (male); 94. T. neiswanderi Johnston and Bruce, 1965 (female).

$\omega$, respectively) (Figs. 56-57, 84, 89). Measurements of leg segments and setae as follows: leg I: Tr 35-38, $p$ R 30-35, Fe 50-52, vF 45-50, Ge 30-35, cG 35-38, $m G$ 39-45, $\sigma 1$ 45-47, $\sigma 2$ 23-28, Ti 27-32, gT 30-34, hT 38-40, $\varphi$ 85-93, Ta (L.) 60-65, Ta (W.) 17-19, $\omega 1$ 17-18, 02 7-8, 13 25-26, $\varepsilon$ 4-5, a a 23-25, ba 18-20, wa 42-44, ra 30-35, la 23-25, d 28-35, e 9-10, f 15-16, p 4, q 4, s 5-6, u 4-5, v 4-5, condylophore 13-15, claw 13-14; leg II: Tr 32-35, pR 32-35, Fe 45-50, vF 50-55, Ge 33-35, c G 28-30, $m G$ 40-43, $\sigma 20-23$, Ti 25-28, gT 30-32, hT 30-33, $\varphi$ 103-110, Ta (L.) 58-62, Ta (W.) 15, w 22-24, ba 18-20, wa 35-40, ra 28-30, la 23-25, d 37-42, e 7-8, f13-15, p 3-4, $q$ 3-4, s 5-6, u 5, v 5, condylophore 12-14, claw 13; leg III: Tr 35-38, sR 38-45, Fe 40-45, Ge 30-35, nG 50-53, $\sigma 20-23$, Ti 28-30, kT 50-53, $\varphi$ 120-125, Ta (L.) 68-75, Ta (W.) 13-15, w 30-33, $r$ 23-25, d 33-37, e 7-8, f 17-20, p 4, q 4, s 5, u 5, v 5, condylophore 13-15, claw 13-15; leg $I V$ : Tr 38-41, Fe 44-46, $w F$ 40-45, Ge 40-42, Ti 36-42, $k T$ 43-50, $\varphi$ 103-110, Ta (L.) 80-83, Ta (W.) 13-15, w 31-34, r 18-20, d 32-38, e 6-8, f 17-20, p 3-4, q 3-4, s 5, u 5-6, v 5-6, condylophore 13-15, claw 12-13; Ge and Ti IV with minute preapical process (Fig. 59). Tarsus IV with seta $r$ filiform (Fig. 94).

Remarks. There are minor differences between our specimens and specimens from New Zealand (Fan and Zhang 2007). (1) Dorsal and ventral setae of Iranian specimens are shorter than those of New Zealand specimens (vi 74-76; ve 40-43; sci 145165; c1 35-38; c2 165-175; cp 145-150; el 280-300; e2 185-210; f2 288-300; h1 275-288; h2 301-306; h3 210-238; 4a 75-78; ps1 188-200; ps2 80-92 vs. vi 87-110; ve 51-63; sci 221-228; cl 45-58; c2 240-251; cp 183-192; el 349-405; e2 262-284; h1 404-449; h2 392-423; h3 300-318; 4a 99-107; ps1 232-238; ps2 118-170). (2) The ratio $s c i / s c e$ is 1.65 vs. 2.1-2.3. (3) Leg setae II-IV of Iranian specimens are shorter (leg II: $\varphi$ 103-110 vs. $\varphi$ 137-176; leg III: $\varphi$ 120-125, $w$ 30-33, r 23-25 vs. $\varphi$ 138-182, w 50-56, r 34-38; leg IV: $\varphi$ $103-110$ vs. $\varphi$ 126-141).

Material examined . Our specimens were collected from the soil and litter under wild cherry plum trees, Prunus cerasifera Ehrh. (Rosaceae), near Giyan, Nahavand region, Hamedan province, Iran ( $\left.34^{\circ} 08^{\prime} 44^{\prime \prime} \mathrm{N}, 48^{\circ} 13^{\prime} 24^{\prime \prime} \mathrm{E}\right)$. They were collected by F. Masoudian on August 19, 2015. All 

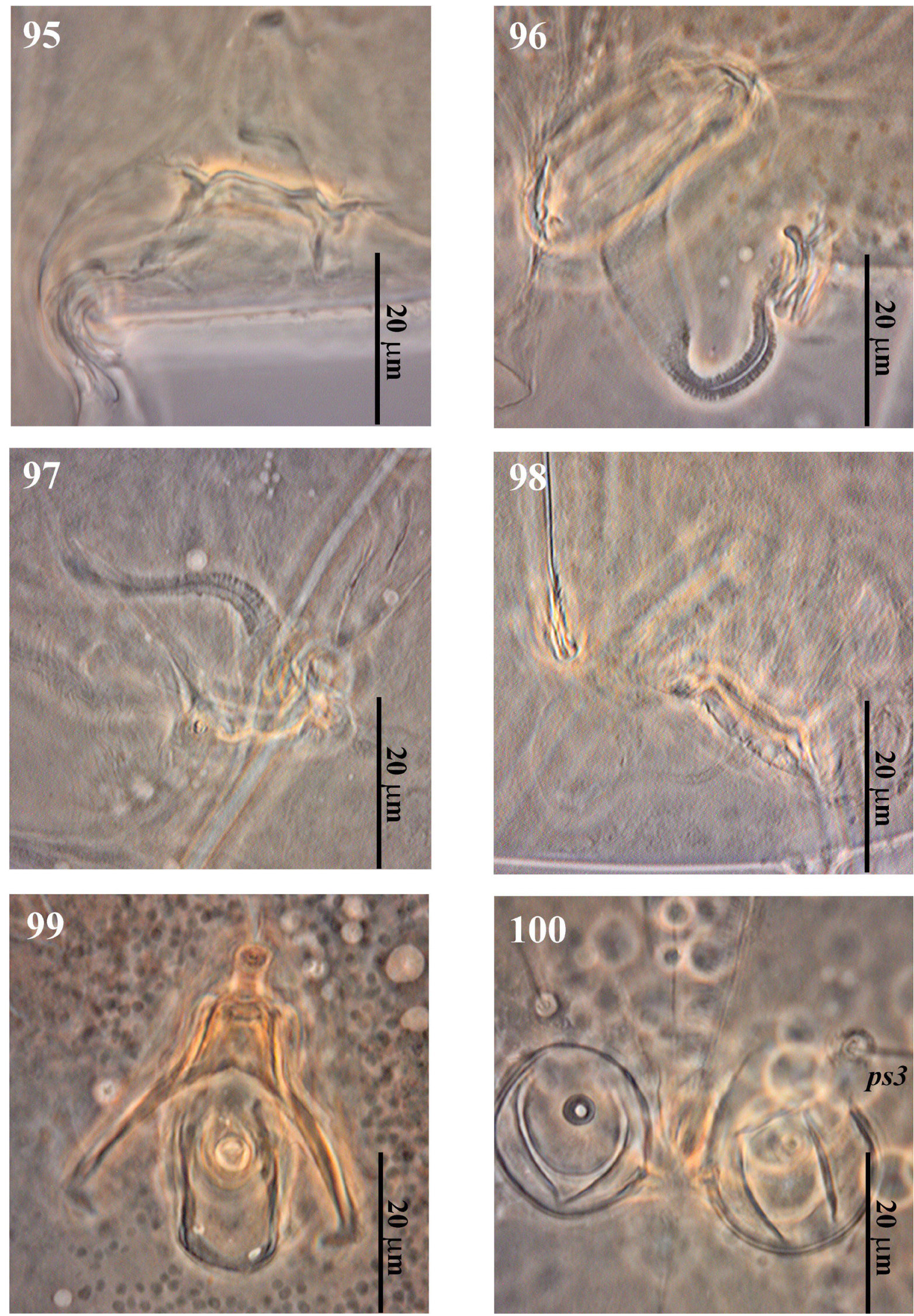

Figs. 95-100. Spermatheca, aedeagus and anal region: 95. T. longior (Gervais, 1844) (female); 96. T. similis Volgin, 1949 (female); 97. T. vanheurni Oudemans, 1924 (female); 98. T. neiswanderi Johnston and Bruce, 1965 (female); 99-100. T. vanheurni Oudemans, 1924 (male). 
specimens have been deposited in the Collection of the Acarology Laboratory, University of Bu-Ali Sina, Hamedan, Iran.

\section{Key to Iranian Tyrophagus species}

(based on Fan and Zhang 2007, except for the treatment of T. putrescentiae, which is followed by Fain and Fauvel 1993, Samšinák 1962; characters of T. brevicrinatus and T. zachvatkini were derived from Samšinák 1962)

1. Dorsal seta $d 1$ and $c l$ subequal 2

- Dorsal seta $d 1$ 1.5-3.2 times longer than seta cl. ...3

2. Supracoxal seta $(s c x)$ short (less than $20 \mu \mathrm{m}$ ) and almost smooth....T. brevicrinatus Robertson, 1959 - Supracoxal seta ( $s c x$ ) long, slender and with pectinations $(40-50 \mu \mathrm{m}) \ldots$. T. similis Volgin, 1949

3. Eyespots present. . .4

- Eyespots absent .5

4. Ratio $d 1 / c 1:>2$; Base of spermathecal sac flat T. putrescentiae (Schrank, 1781)

- Ratio d1/c1: 1.5-1.8; Base of spermathecal sac funnel-shaped.

..T. neiswanderi Johnston and Bruce, 1965

5. Dorsal seta $d 1$ 2.4-3.2 times longer than seta c1.

- Dorsal seta $d l$ at most twice as long as seta c1.......

6. Tarsus IV with $w$ and $r$ setae spiniform, spermathecal duct wide, tarsus I with short, stout and apically clavate solenidion $\omega 1$.

T. perniciosus Zakhvatkin, 1941

- Tarsus IV with $w$ and $r$ setae filiform, spermathecal duct slender, tarsus I with slender solenidion w1 ........................T. vanheurni Oudemans, 1924 [=T. palmarum Oudemans; sensu Robertson, 1959 (Fan and Zhang, 2007)]

7. Solenidion I $\omega 1$ cylindrical, tapered distally ... T. longior (Gervais, 1844)

— Solenidion I $\omega 1$, not tapered distally.... T. zachvatkini Volgin, 1948

\section{ACKNOWLEDGEMENTS}

This paper is a part of the Ph.D. thesis of the senior author, who was financially supported by Bu-Ali Sina University, Hamedan, Iran. The authors are very grateful to Dr. Pavel B. Klimov (University of Michigan, Ann Arbor, USA and Tyumen State University, Tyumen, Russia) and Prof. Edward A. Ueckermann (School of Environmental Sciences and Development, NorthWest University, Potchefstroom, South Africa;
ARC-Plant Protection Research Institute, Queenswood, Pretoria, South Africa) for providing valuable suggestions on the draft of this manuscript.

\section{REFERENCES}

Fain, A. and Fauvel, G. 1993. Tyrophagus curvipenis n.sp. from an orchid cultivation in a greenhouse in Portugal (Acari: Acaridae). International Journal of Acarology, 19 (1): 95-100.

Fan, Q.-H. and Zhang, Z.-Q. 2007. Tyrophagus (Acari: Astigmata: Acaridae). Fauna of New Zealand, 56. $291 \mathrm{pp}$.

Grandjean, F. 1939. La chaetotaxie des pattes chez les Acaridae. Bulletin de la Société Zoologique de France, 64: 50-60.

Gervais, F.L.P. 1844. Acarides. In: Walckenaer's Histoire Naturelle des Insectes. Aptères. Vol. 3, pp. 260-266.

Griffiths, D.A.,Atyeo, W.T., Norton, R.A. and Lynch, C.A. 1990. The idiosomal chaetotaxy of astigmatid mites. Journal of Zoology, London, 220: 1-32.

Haddad Irani-Nejad, K., Rahgozar, M. and Valizadeh, M. 2007. Astigmatic mite fauna of alfalfa fields and their distribution in South West of East Azarbaijan province. Journal of Agricultural science, 17 (1): 127-137. [In Persian with English abstract]

Hughes, A.M. 1976. The Mites of Stored Food and Houses, $2^{\text {nd }}$ ed. Ministry of Agriculture, Fisheries and Food, Technical Bulletin no. 9. Her Majesty's Stationery Office, London. 400 pp.

Johnston, D.E. and Bruce, W.A. 1965. Tyrophagus neiswanderi, a new acarid mite of agricultural importance. Research Bulletin of Ohio Agricultural Experimental Station, 977: 1-17.

Kamali, K., Ostovan, H. and Atameh, A. 2001. A Catalog of Mites and Ticks (Acari) of Iran. Islamic Azad University Scientific Publication Center, 196 pp.

Khanjani, M., Kamali, K. and Mosaddegh, M.S. 2000. The Acari fauna of Astigmata of legumes in Hamadan, Iran. The Journal of Agricultural Science, 9 (4): 27-41.

Klimov, P.B. and OConnor, B.M. 2003. Phylogeny, historical ecology and systematics of some mushroom-associated mites of the genus Sancassania (Acari: Acaridae), with new generic synonymies. Invertebrate Systematics, 17: 469-514.

Latreille, P.A. 1802. Histoire naturelle, générale et particulière des crustaces et des insectes. Vol. 3. F. Dufart, Paris, $467 \mathrm{pp}$.

Lotfollahi, P., Haddad Irani-Nejad, K., Bagheri, M. and Valizadeh, M. 2010. Astigmatic soil mites fauna of alfalfa fields: record of two new mites of the family Histiostomatidae and their distribution in Northwest of East Azarbaijan Province. Journal of Plant Protection, 24 (3): 303-314. [In Persian] 
OConnor, B.M. 2009. Cohort Astigmatina (Chapter sixteen). In: G.W. Krantz and D.E. Waiter (Eds.). A Manual of Acarology. $3^{\text {rd }}$ edition. Texas Tech University Press, pp. 565-657.

Oudemans, A.C. 1924. Acarologische aanteekeningen LXXVII. Entomologische Berichten 136 (VI): 317-336.

Robertson, P.L. 1959. A revision of the genus Tyrophagus, with a discussion on its taxonomic position in the Acarina. Australian Journal of Zoology, 7 (2): 146-181.

Samšinák, K. 1962. Beiträge zur Kenntnis der Gattung Tyrophagus Oudemans. Acta Societatis Entomologicae Čechosloveniae, 59 (3): 266-280.
Schrank, F.P. 1781. Enumeratio Insectorum Austriae Indigenorum. August Vindelicor, Klett, 548 pp.

Volgin, V.I. 1948. New species of mites of the genus Tyrophagus Ouds., 1923 (Tyroglyphidae, Acarina). Doklady Akademii Nauk USSR, Zoology, 60 (3): 509-511. [In Russian]

Volgin, V.I. 1949. Materials on systematics of mites of the genus Tyrophagus Ouds., 1923 (Tyroglyphidae, Acarina). Doklady Akademii Nauk USSR, Zoology, 65 (3): 385-388. [In Russian]

Zakhvatkin, A.A. 1941. Fauna of U.S.S.R. Arachnoidea. Vol. VI, No. 1: Tyroglyphoidea [Acari]. American Institute of Biological Sciences, Washington DC. 573 pp. [Translated by A. Ratcliffe; A.M. Hughes, 1959] 